\title{
ELABORAÇÃO DO BALANCED SCORECARD ALINHADO AOS OBJETIVOS DA UNIVERSIDADE FEDERAL DE SANTA CATARINA: UM ESTUDO DE CASO NA EDITORA DA UFSC
}

\author{
ELABORATION OF THE BALANCED SCORECARD ALIGNED TO THE OBJECTIVES OF THE \\ FEDERAL UNIVERSITY OF SANTA CATARINA: A CASE STUDY AT THE UFSC EDITOR
}

\section{JOÃO HENRIQUE COSTA}

Universidade Federal de Santa Catarina (UFSC)

Mestre em Ciências Contábeis - UFSC

Orcid: https://orcid.org/0000-0002-9313-2218 / E-mail: professorjhc@hotmail.com

R. Eng. Agronômico Andrei Cristian Ferreira, s/n - Trindade, Florianópolis - SC, 88040-900

\author{
SÉRGIO MURILO PETRI \\ Professor do PPG em Contabilidade e do PPG em Controle de Gestão \\ Universidade Federal de Santa Catarina (UFSC) \\ Doutor em Engenharia de Produção - Universidade Federal de Santa Catarina (UFSC) \\ Orcid: https://orcid.org/0000-0002-1031-7939 / E-mail: smpetri@gmail.com
}

Submissão: 04/11/2020. Revisão: 14/04/2021. Aceite: 26/05/2021. Publicação: 02/07/2021.1

DOI: http://dx.doi.org/10.22277/rgo.v14i3.5865

\section{RESUMO}

Propor painel de desempenho, pelo instrumento Balanced Scorecard, para a Editora da Universidade Federal de Santa Catarina com medidas alinhadas aos objetivos da Plano de Desenvolvimento Institucional (2015-2019). Por isso, foi necessário organizar por meio dos objetivos específicos, como: operacionalizar a estratégia; integrar o Plano de Desenvolvimento Institucional com os objetivos estratégicos; e elaborar o painel de desempenho. O mapa estratégico e o Balanced Scorecard foram configurados mediante às interações com os gestores da Editora, por meio de entrevistas, questionários e observações do cotidiano da Editora, em seus setores. Os resultados mostram a integração e o alinhamento institucional, por meio do mapa estratégico e elaboração do painel de desempenho do Balanced Scorecard, como também o refinamento do Balanced Scorecard. A observação estratégica da Editora da Universidade Federal de Santa Catarina proporcionou a identificação das perspectivas de clientes, processos internos e aprendizado e crescimento. Essas perspectivas se delineiam em 11 objetivos estratégicos que formam os 13 indicadores de desempenho, é identificada a situação atual, das metas, e a iniciativa para atingir as metas estabelecidas. Foi identificado que a Editora, no ponto inicial da pesquisa, obtinha o resultado do desempenho negativo em 6 pontos, pois não tinha, efetivamente, um modelo que alinhasse a sua estratégia a suas metas e iniciativas. Porém, com o acompanhamento de, aproximadamente, um ano pelo pesquisador, que faz parte do operacional da instituição, e a aplicação do modelo Balanced Scorecard, ao qual sugere-se em seu desenvolvimento as metas e iniciativas, o resultado apresentou o desempenho de 86 pontos positivos.

Palavras-chave Balanced Scorecard. Estratégia. Instituições de Ensino Superior.

Este é um artigo publicado em acesso aberto (Open Access) sob a licença Creative Commons Attribution, que permite uso, distribuição e reprodução em qualquer meio, sem restrições desde que o trabalho original seja corretamente citado. 
Elaboração do Balanced Scorecard alinhado aos objetivos da Universidade Federal de Santa Catarina: Um estudo de caso na Editora da UFSC

\begin{abstract}
It focuses on the proposal of a performance panel, provided by the instrument Balanced Scorecard (BSC), to Editora da Universidade Federal de Santa Catarina (EdUFSC), with procedures adapted according to the UFSC's Institutional Development Plan 2015-2019 (PDI in Portuguese). Thus, it was necessary to align some Editora's functions with its specific objectives, for instance: to operationalize the strategies and integrate them with UFSC'S PDI; and to elaborate the performance panel of EdUFSC. The strategic map and the BSC were developed according to the interactions made with the Editora's directors, such as interviews, questionnaires, and daily observations of different sectors. The results show an institutional integration and conciliation between EdUFSC and PDI 2015-2019, through the elaboration of the strategic map and the BSC's performance panel, as well as the improvement of BSC's method. The strategic observation at EdUFSC provided the identification of the clients' perspective, its internal processes, and the opportunity to learn and grow. These perspectives are based on eleven (11) strategic objectives, which compose the thirteen (13) development indicators. It was possible to identify the Status Quo, the goals, and the initiative to achieve the proposed objective. The synthesis of the results converges to the global assessment analysis about EdUFSC's performance, which has, as a reference, a negative rate of six (6) points, since it did not have an effective model which could align its strategies to its goals. However, due to the application of BSC's model, which is suggested to work with goals and campaigns, its performance increased by eighty-six (86) positive points.
\end{abstract}

Keywords: Balanced Scorecard. Strategic. Higher Education Institutions.

\title{
1 INTRODUÇÃO
}

As instituições são fórmulas inacabadas e necessitam de aprimoramentos em todo o período que existirem. Mesmo que obtenham sucesso em alguma perspectiva, pode haver outros prismas que precisam ser aprimorados se comparados com concorrentes ou com metas/objetivos ainda a ser conquistado. Avaliação de desempenho organizacional é um tema de grande interesse profissional, e acadêmico, pois gera vantagens competitivas, garante a sustentabilidade, e perspectivas de continuidade, por meio do melhoramento da gestão das suas atividades (DIMITROPOULOS; KOSMAS; DOUVIS, 2017).

O sistema de medição é tema de crescente discussão tanto para os acadêmicos, como profissionais de mercado, pois é necessário evidenciar o comprometimento da gestão da organização com o desempenho dela mesma. A organização precisa analisar o desempenho e projetar objetivos e metas que aprimorem gestão por meio de um sistema de medição, em um período temporal, e sistemático, melhorando o desenvolvimento da sua gestão. Os problemas com os sistemas de medição existentes, em particular, se baseiam em princípios de contabilidade tradicionais, porém cientificamente a contabilidade gerencial tem sido amplamente discutida e ampliada, melhorando a abordagem gerencial das entidades (BITITCl; CARRIE; MCDEVITT, 1997; NEELY, 2005; NUDURUPATI et al., 2011).

A adoção de sistema de avaliação de desempenho simplista pode ser algo danoso à observação, pois pode existir o viés, ou tendência, em avaliar o desempenho com base em pouca complexidade. Como exemplo, pode-se observar o desempenho do custo e da eficiência, contudo, e fica evidente que existem outros critérios importantes para essa medição, e essa simplicidade do sistema de avaliação conduzirá à fragilidade do sistema de avaliação. Então, Neely (1995), faz crítica com relação à performance obtida por meio de um 
sistema de medição, e nos conduz para a análise de alguns pontos relevantes, ao qual expõem questionamentos com relação a medida de desempenho utilizada, a sua utilização, ao custo de implementação e os benefícios que serão agregados.

As instituições de ensino superior privando pelo seu papel social encaram distintos compromissos, destacando-se: a diminuição de recursos, evolução quantitativa de instituições de ensino superior, competitividade na captação de seus clientes, política de mercantilização e acesso ao ensino superior (TAYLOR; BAINES, 2012). Contudo, para as instituições mantiverem sucesso perante os desafios é preciso alcançar os objetivos vislumbrados é necessário que ocorra o monitoramento, controle e aprimoramentos. O mecanismo que pode contribuir são as medidas de desempenho, pois critica os objetivos organizacionais, como também descreve o cenário atual da entidade (AL-TURKI; DUFFUAA, 2003; TAPINOS; DYSON; MEADOWS, 2005).

A pesquisa operacional tem o entendimento racional para a decisão mais assertiva em relação ao desempenho de uma organização. Consiste na percepção, por meio de determinado modelo, sobre desempenho, mediante aos instrumentos de medição que transpareça o desejo a ser alcançado (DE ANDRADE; 1998, LONGARAY, 2017.)

Nesse contexto, de avaliação de desempenho, dentre as 34 ferramentas encontradas por Petri (2005), destaca-se o Balanced Scorecard. Tem-se popularizado o BSC no meio profissional, pois é uma ferramenta que visa a medição do desempenho, o gerenciamento estratégico e informação que visa, e compreende, a melhoria da gestão (NEELY, 2005; KAPLAN; NORTON, 1997). Apesar de se passarem décadas do início dos estudos sobre o BSC, a relevância acadêmica continua vigorosa, pois existem várias publicações sobre o assunto até os dias atuais (SOUZA et al., 2015).

Entende-se que as instituições são entidades sempre em formação e aprimoramento e que sempre é necessário fazer uma análise de cenários, diagnósticos e ações com o intuito de melhorias na gestão, é preciso uma verificação de pontos distintos, tanto financeiros como gerenciais. A adoção de sistemas de medição de desempenho adota um determinado padrão quantificável, sistemático, controlável e que existe um indicador que é um instrumento de medição. Por meio da implementação de um sistema de indicadores, para aquilo que the quer verificar, o gestor pode quantificar a performance do desempenho operacional da entidade (CHEN; WANG; YANG, 2009).

No contexto da análise de desempenho é necessário o aperfeiçoamento científico na área pública, principalmente no Brasil, pois os estudos retratam uma tendência da análise em instituições privadas em relação instituições governamentais. Então, é importante ter um volume engrandecido de estudos governistas para que se possa retratar uma determinada realidade e ter informações para a melhoria da gestão. O desenvolvimento de argumentos para refletir a verdade inserida na Editora da UFSC e a melhoria da gestão organizacional, por intermédio da ciência, pode ser crucial para apoiar a expansão da estrutura, ampliação das atividades de produção, comercialização e divulgação de todas as obras produzidas, de cunho didático, científico ou literário.

O presente estudo visa, não só, ampliar o horizonte de pesquisas sobre a avaliação de desempenho na área pública dentro de uma editora universitária, como também propor alternativas por meio da análise das informações cotidianas e sugerir um modelo que possa surtir efeito na redução de tempo, melhoria da estrutura, comunicação, transparência, eficiência e financeiro.

Com base em todas as premissas introdutórias e atendendo ao estabelecido para a proposição de um modelo de avaliação de desempenho, por intermédio da ferramenta BSC, 
Elaboração do Balanced Scorecard alinhado aos objetivos da Universidade Federal de Santa Catarina: Um estudo de caso na Editora da UFSC

com o foco na avaliação a instituição mediante a estratégia da Editora da UFSC, para a busca da sustentabilidade, surge o seguinte questionamento: Quais indicadores estão alinhados a estratégia, de autossustentação, para gerenciamento da Editora da Universidade Federal de Santa Catarina?

A pesquisa tem como objetivo principal em propor um modelo de painel de desempenho, pelo instrumento Balanced Scorecard, para a Editora da UFSC com medidas alinhadas a estratégia da instituição/abertura de mercado. E delineia-se nos objetivos específicos em: Operacionalizar a estratégia da Editora da UFSC; Integrar o PDI da UFSC com os objetivos estratégicos da Editora da UFSC; e elaborar o painel de Desempenho da Editora da Universidade Federal de Santa Catarina.

A avaliação de desempenho é foco de observação para as organizações, e tem bastante relevância para as entidades, pois procuram evidenciar com transparência todo o direcionamento e planejamento (PETRI, 2005). Dentro das 34 alternativas (PETRI, 2005) justifica-se a operacionalização do Balanced Scorecard por se tratar de instrumento que concede a visualização do alinhamento do departamento, diretoria, secretarias e outros, com a estratégia institucional. Esse "ao encontro" entre as subdivisões com a instituição é benéfico, pois garante a maximização no atingimento dos resultados esperados e compreendem a sincronização organizacional em prol da melhoria da gestão (CHEN; WANG; YANG, 2009; PEREIRA; TERRA, 2016). O BSC evidencia a visão e estratégia organizacional como foco principal, deixando controle em segundo plano, por ser uma ferramenta continuada que segue os pontos principais da estratégia, desenvolvendo e monitorando indicadores (KAPLAN; NORTON, 1993, 2000).

$\mathrm{Na}$ instituição pública, dentro da editora universitária, podem existir falhas na gestão de pessoas, processos internos desajustados, não haver planejamento financeiro e outros fatores que interferem no cotidiano das tarefas executadas pela Editora. Então, esse estudo vem ao encontro da estratégia institucional, e visa fornecer subsídios por meio da proposição de um modelo de avaliação de desempenho que auxilie a gestão da unidade, analisando a situação planejada e comparando o cenário atual. O estudo traz consigo o ensejo de beneficiar a gestão pública analisando o desempenho e sugerindo melhorias, contribuindo com a evolução na eficiência.

Sobre a delimitação da pesquisa vislumbra-se que a pesquisa é realizada em apenas uma editora universitária do Brasil e verifica a alinhamento estratégico da editora com a instituição. Ou seja, observar-se-á de qual modo o departamento, diretoria ou demais órgãos, está alinhado com a estratégia institucional e tentar corrigir as falhas. O foco principal da pesquisa delimita-se na observação da Editora da UFSC. Verificar-se-á, quanto ao tempo, o Plano de Desenvolvimento Institucional (PDI) (2015-2019), que é o relato instrumental de planejamento essencial para a pesquisa sobre a gestão estratégica do presente estudo, porém a observação é feita em tempo médio de um ano, desde o início do processo até a proposta do BSC.

\section{REVISÃO DA LITERATURA}

A gestão pública tem seus desafios atrelados ao tempo que há o atendimento das necessidades do público que precisa de tal serviço. Sempre há barreiras a serem superadas e deficiências a ser equacionada, porém é necessário delinear por meio da apresentação de um resumo sobre administração pública tradicional, da New Public Management e da abordagem emergente (BRYSON; CROSBY; BLOOMBERG, 2014). As posturas são importantes, pois 
identificam qual direcionamento existe sobre a gestão pública no atual cenário. Conforme os autores, a criação do processo democrático, na abordagem emergente, proporciona discussão, e reflexão, responderá tão somente à cidadania vigorosa, principalmente pelo fato de que o que é coletivo tem que ser valorizado para o bem da coletividade, ou seja, a democracia.

A gestão pública está inserida em instituições públicas de ensino superior com o intuito de transformar, por meio da educação, os recursos direcionados por políticas públicas, democráticas, que visam o desenvolvimento da nação por meio da qualificação de cidadãos, melhoria econômica, aprimoramento de medicamentos, divulgação científica, desenvolvimento tecnológico e outros. Então, as universidades públicas federais têm papel fundamental para o crescimento brasileiro em relação à pesquisa, ensino e extensão, pois precisam ter eficiência na aplicação de recursos para obter um resultado satisfatório perante a sociedade, que é o seu principal devedor e credor. E para qual, precisam ser avaliadas em seu desempenho de alguma forma.

O ensino superior no Brasil pode ser oferecido por quatro tipos de instituições: Universidades, Centros Universitários, Faculdades e Institutos de Educação, Ciência e Tecnologia, ao qual oferecem a graduação na forma de bacharelado, licenciatura e formação tecnológica. Por sua vez, os cursos de pós-graduação são divididos entre lato sensu (especializações e MBAs) e stricto sensu (mestrados e doutorados). Hoje em dia são ofertados na modalidade em EAD e presencial, há predominância de matriculados com o sexo feminino na graduação, e o grande acesso é por cursos de bacharelado, sendo o período noturno o mais procurado (INSTITUTO NACIONAL DE ESTUDOS E PESQUISAS EDUCACIONAIS ANÍSIO TEIXEIRA, 2017; SILVEIRA; PETRI, 2019).

A importância das instituições de ensino superior denota no seu papel social que são relevantes por tudo que representam, desenvolvem, aprimoram pela inovação científica e tecnológica, contudo, precisam apresentar razoabilidade na aplicação de recursos em busca da melhoria da qualidade de vida do brasileiro, seja em qual cenário se encontre, porém com muita responsabilidade.

Na relação institucional permeiam distintas subdivisões que lastreiam o ambiente organizacional, porém, dentre importâncias diversas de toda instituição há um órgão que tem relevância e reconhecimento por seus serviços prestado e faz parte da observação nesta pesquisa, esse órgão é a Editora da Universidade Federal de Santa Catarina.

A Editora é responsável pela divulgação, produção, distribuição e comercialização das obras que foram produzidas, principalmente por professores e técnicos administrativos da UFSC, tem sua base organizacional reforçada pela atividade principal da divulgação da evolução tecnológica, científica e literária, e através da aprovação das obras, que são submetidas ao crivo do qualificado conselho editorial, que torna justa a continuidade da sua existência pela prestação de serviços editoriais, com qualidade inquestionável (UFSC, 2019). O seu negócio tem como ofício: a) ofertar obras impressas de relevância acadêmica e literária com o selo da EdUFSC, com preços de capa competitivos; b) atender a demanda dos alunos de graduação, pós-graduação e comunidade em geral local, nacional e internacional; e c) ofertar e-books em acesso aberto (UFSC, 2019).

\subsection{AVALIAÇÃO DE DESEMPENHO}

Para embasar a avaliação de desempenho é necessário ter como premissa o que está sendo discutido cientificamente, porém, não existe uma definição clara sobre a sua amplitude. Contudo, entende-se como sendo o processo de mensuração da eficiência e eficácia de 
Elaboração do Balanced Scorecard alinhado aos objetivos da Universidade Federal de Santa Catarina: Um estudo de caso na Editora da UFSC

determinada ação, ao qual os indicadores ou medidas de desempenho são quantificáveis mediante a apuração de métricas, específica ao caso (NEELY; GREGORY; PLATTS, 1995). A intensão da estruturação das métricas segue um critério inicial, assim a junção do conjunto de métricas pode definir o que pode ser medido, porém quando há isolamento da métrica pode ser ineficiente para fazer a medição. Para entender a eficácia é necessário que esteja atrelada aos objetivos e estratégia, reforçando os indicadores de desempenho, e enaltecendo suas variáveis (NEELY; GREGORY; PLATTS, 1995; LEBAS, 1995; OTLEY, 2001).

O desempenho é multidimensional e não deve ser visualizado apenas uma dimensão, como também é difícil afirmar que existam medidas comuns de eficácia que ocorram em organizações que divergem de objetivos e estratégias, porém podem existir no nível mais simplório (OTLEY, 2001). A união dos indicadores de desempenho viabiliza a construção de um sistema de avaliação de desempenho, que tem a capacidade de apoiar o processo de decisão por meio da coleta, análise e informação (NEELY; GREGORY; PLATTS, 1995; VAN CAMP; BRAET, 2016).

Esse sistema de medição de desempenho é descrito em três distintos níveis: medidas individuais, conjunto de medidas individuais e a relação entre o sistema e o ambiente. 0 sistema precisa se inter-relacionar com o ambiente interno, seja pela cultura ou valores, como com o ambiente externo, por seus clientes ou concorrentes. E as métricas precisam ser entendidas a sua criação específica, para, assim, atender objetivos divergentes inseridos na organização, pois existem aspectos de desempenho relevantes para cada propósito interessado (NEELY; GREGORY; PLATTS, 1995; LEBAS, 1995; OTLEY, 2001).

Nas pesquisas realizadas sobre avaliação de desempenho da gestão universitária é observável que há relevância do tema pelos cientistas nas últimas décadas, pois é necessário avaliar a medida de desempenho das instituições tendo como parâmetro o aumento de pesquisas que tentam avaliar esse desempenho. Avaliação de desempenho organizacional é atualmente um tema de grande interesse profissional e acadêmico, pois visa gerar vantagens competitivas e ainda garante possibilidade de sustentabilidade, e consequentemente, a continuidade da organização (DIMITROPOULOS; KOSMAS; DOUVIS, 2017).

Foi feito a aplicação do instrumento de pesquisa ProKnow-C sobre o tema avaliação de desempenho e se desenvolveu um relato de estudos que tenham relevância neste tema. Com o entendimento de melhorias na observação dos artigos, subtraindo as publicações em congressos, conferências e outros do gênero, foi apenas considerado os documentos publicados em revistas ou jornais com relevância, fazendo uma filtragem para enriquecer a pesquisa. Para evidenciar alguns dos modelos, ferramentas ou sistemas de medição de desempenho é elaborado por meio da investigação do portfólio, que fez uma verificação unificada com os estudos de Coelho (2019) e de Silveira e Ensslin (2017), para identificar estudos empíricos que utilizam tais instrumentos de avaliação de desempenho.

Há uma gama de ferramentas utilizadas para avaliar o desempenho na gestão universitária, porém, dentro da lista das importantes ferramentas mencionadas pelos autores, destaca-se o BSC. O Balanced Scorecard é um sistema de medição de desempenho e de gestão estratégica, que permite a organização comunicar-se, mediante pontos estratégicos, e convergir esse esforço estratégico em ações para melhoria da eficiência (KAPLAN; NORTON, 1993, 1997, 2001; CHEN; WANG; YANG, 2009). 


\subsection{BALANCED SCORECARD}

Para avaliar o desempenho, dentre todas as ferramentas existentes, o Balanced Scorecard traz consigo a ideia de ser um instrumento que traduz a visão e a estratégia da empresa num conjunto coerente de medidas de desempenho, isso é de suma importância para os gestores. Pensando em avaliação de desempenho, "o Balanced Scorecard é, para os gestores, um instrumento completo que traduz a visão e a estratégia da empresa num conjunto coerente de medidas de desempenho" (KAPLAN; NORTON, 1997, p. 19).

O principal motivo para a confecção do BSC é que os gestores tenham a capacidade de mensurar como diversas partes da organização criaram o seu valor, mediante ao tempo, e no mesmo instante ainda mantém o interesse no desempenho financeiro. Ou seja, criam um sistema gerencial para a organização a partir do BSC, conforme demonstrado na Figura 1.

Para Lunkes (2007), o BSC integra a composição de medidas de desempenho que derivam da estratégia organizacional. Essas medidas direcionam, monitoram e avaliam o aprimoramento dos objetivos estratégicos da organização. Sendo assim, o BSC contribui com a gestão do alto escalão da organização na condução da estratégia, facilitando que os empregados entendam e desenvolvam ações com o intuito de alcançar objetivos e metas; consequentemente, o BSC apoia a estratégia no cotidiano dos negócios.

Pensando em Estratégia organizacional é importante relatar a ferramenta criada pelos autores Kenneth Andrews e Roland Cristensen, docentes da Harvard Business School, e utilizada como ferramenta estratégica organizacional no meio acadêmico, o instrumento de análise SWOT identifica a competitividade de uma organização segundo quatro premissas básicas: Strengths (Forças), Weaknesses (Fraquezas), Oportunities (Oportunidades) e Threats (Ameaças). Essas as premissas da organização para a matriz, torna-se evidente a sincronização por meio da análise das forças e fraquezas da empresa, das oportunidades e ameaças do meio em que a empresa atua. Se a organização obtiver um alinhamento dos pontos fortes com os fatores críticos de sucesso para satisfazer as oportunidades de mercado, a tendência é que tenha competitiva (KOTLER, 2000; RODRIGUES et al., 2005; DAYCHOUW, 2007).

A funcionalidade da Matriz SWOT é enlaçar as oportunidades e ameaças externas na visualização juntamente com os pontos fortes e pontos fracos, ou seja, é uma avaliação estratégica por meio de um instrumento consagrado por sua utilização na gestão estratégica competitiva. $O$ entendimento de fazer uma relação entre as quatro zonas servem de indicador de um cenário da organização, ressaltando perspectivas distintas para o mesmo foco, com observação sincronizada da matriz. (CHIAVENATO; SAPIRO, 2003)

Entendendo o processo, que se deve alinhar aos objetivos estratégicos, então o BSC era pensado para organizações com fins lucrativos, porém a utilização do BSC vem tomando vários adeptos de outras áreas. Porém, a dentre as diversas áreas, as que descrevam a sua aplicabilidade em instituições de ensino superior são fontes de pesquisas recentes (CHEN; YANG; SHIAU, 2006; PAPENHAUSEN; EINSTEIN, 2006; KETTUNEN, 2008; PHILBIN, 2011; CHEN; WANG; YANG, 2009; TAYLOR; BAINES, 2012; ISMAIL; AL-THAOIEHIE, 2015; PIETRZAK; PALISZKIEWICZ; KLEPACKI, 2015; SENARATH; PATABENDIGE, 2015; COSTA; SOUZA; PETRI, 2018; COELHO, 2019; SILVEIRA; PETRI, 2019).

Pensando em como medir o desempenho, a composição do sistema de medição está disposta por meio da sinergia entre as medidas individuais em busca da mesma estratégia, e pode trazer benefícios maiores quando analisada a estratégia de forma conjunta, já quando a análise é individual pode haver perda de alinhamento com a estratégia organizacional, ocasionando ineficiência ou ineficácia no processo.

Quanto aos princípios da organização, que tem o foco na estratégia, é necessário 
Elaboração do Balanced Scorecard alinhado aos objetivos da Universidade Federal de Santa Catarina: Um estudo de caso na Editora da UFSC

entender a Figura 1, que denota todo o processo para o alinhamento estratégico institucional.

Figura 1 - Princípios da Organização com foco na Estratégia

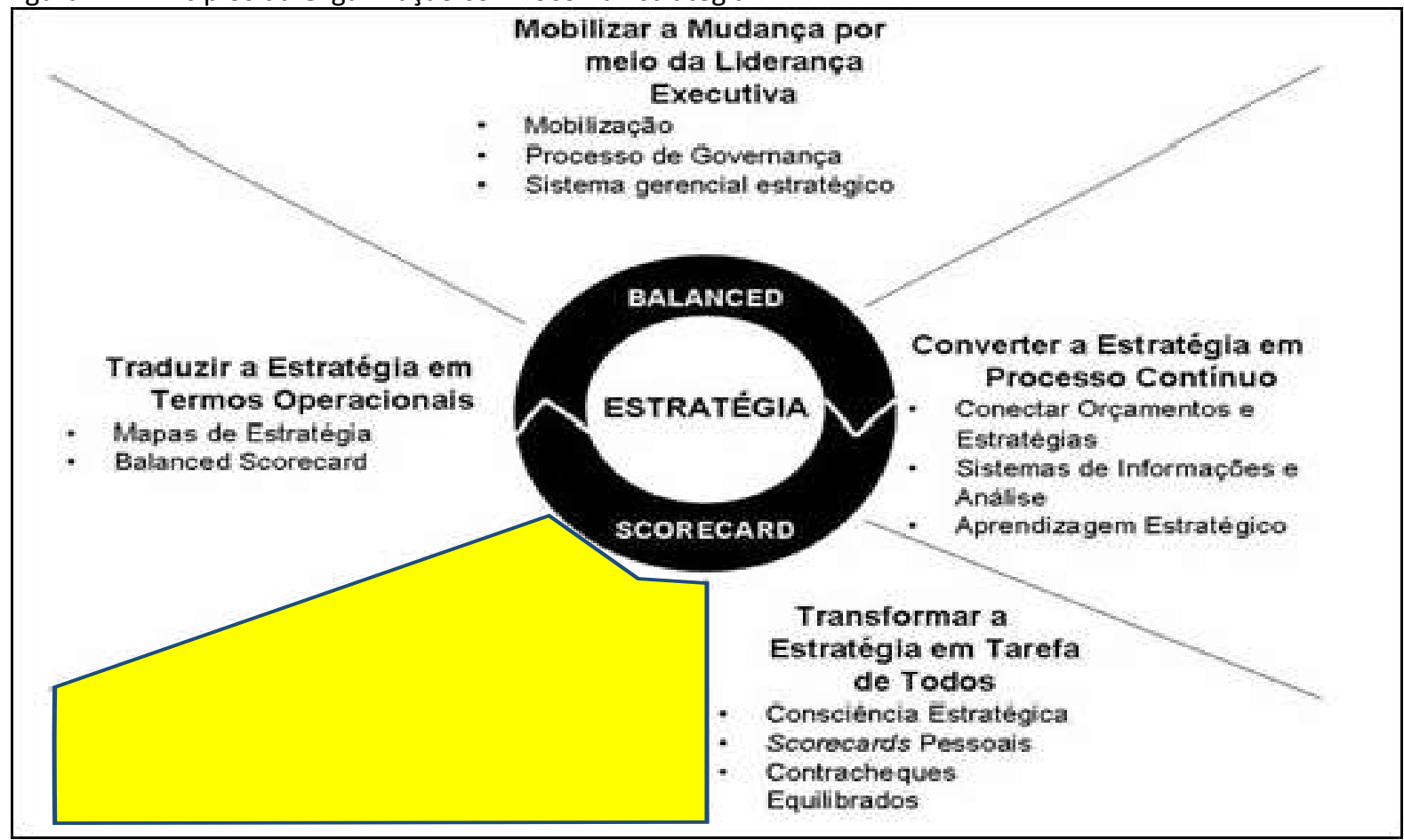

Fonte: Kaplan e Norton (2000, p. 19).

As organizações do setor privado vislumbram o lucro, continuidade e melhoria da gestão. Porém, as organizações públicas atendem aos serviços coletivos, integrando a gestão, legalidade e responsabilidade social. O BSC aplicado em organizações públicas pretende adaptar as suas perspectivas, para que essas especificações e regras pertencentes ao setor público sejam preservadas.

Quando a observação se volta ao ambiente em que estão inseridas as instituições de ensino superior é notório fazer o relato de que algumas pesquisas são importantes para o desenvolvimento de estudos, pois possuem características semelhantes, com o foco em análise de desempenho pelo instrumento BSC. Ou seja, existem estudos que influenciaram o estudo aqui realizado em órgão público, principalmente voltado para a aplicação em instituições de ensino superior. Pela similaridade com a presente pesquisa, destaca-se Rosa et al. (2014); Coelho et al. (2017) e Silveira e Petri (2019), pois são os que apresentam maior alinhamento com a presente pesquisa, tendo a virtude de sugerir a aplicação de um modelo de BSC que se aplique a uma determinada instituição. Coelho et al. (2017) e Silveira e Petri (2019) se assemelham ainda mais, por aplicarem também um BSC em uma Instituição de Ensino Superior Pública. Assim como os estudos de Coelho (2019) que abrangeram uma análise bibliométrica, com base na Web of Science, de 1992-2017, sobre o Balanced Scorecard foi importante para entender algumas lacunas de estudo.

\subsection{PESQUISAS ANTERIORES}

Quando a observação se volta ao ambiente em que estão inseridas as instituições de ensino superior é notório fazer o relato de que algumas pesquisas são importantes para o desenvolvimento de estudos, pois possuem características semelhantes, com o foco em análise de desempenho pelo instrumento BSC. Ou seja, existem estudos que influenciaram o 
estudo aqui realizado em órgão público, principalmente voltado para a aplicação em instituições de ensino superior, conforme exposto no Quadro 1.

Quadro 1 - Estudos Anteriores sobre BSC

\begin{tabular}{|c|c|c|}
\hline Autores & Anos & Estudos \\
\hline Boland e Fowler & 2000 & Desenvolveu perspectiva de gestão de desempenho em órgão público \\
\hline Radnor e McGuire & 2004 & Verificou a gestão de desempenho no setor público \\
\hline Kanji e Moura e Sá & 2007 & Implementação de modelo e a importância de medir o desempenho. \\
\hline Verbeeten & 2008 & $\begin{array}{l}\text { Analisou as práticas de gestão de desempenho em organizações do setor } \\
\text { público }\end{array}$ \\
\hline Schalm & 2008 & $\begin{array}{l}\text { Desenvolvimento de um BSC corporativo facilitado pensamento } \\
\text { estratégico executivo e esclarecido direção estratégica da organização }\end{array}$ \\
\hline Herbohn et al. & 2012 & $\begin{array}{l}\text { Analisar as experiências de implementação do BSC de uma organização } \\
\text { do setor público }\end{array}$ \\
\hline Nuti, Seghieri e Vainieri & 2012 & Avaliou a eficácia de um sistema de avaliação de desempenho \\
\hline Rosa & 2014 & Implementação do BSC em uma instituição \\
\hline Coelho, Vicente & 2017 & Implementação do BSC em uma instituição pública \\
\hline Silveira, Ensslin & 2017 & Avaliação de Desempenho em Instituições de Ensino Superior - BSC \\
\hline Coelho et al. & 2017 & $\begin{array}{l}\text { Implementação do BSC em uma instituição pública - Departamento de } \\
\text { contabilidade da UFSC }\end{array}$ \\
\hline
\end{tabular}

Fonte: dados da pesquisa (2019).

Todas as pesquisas relatadas foram importantes para o desenvolvimento da ciência. Pela similaridade com a presente pesquisa, destaca-se Rosa et al. (2014) e Vicente et al. (2017), pois são os que apresentam maior alinhamento com essa presente pesquisa, tendo a virtude de sugerir a aplicação de um modelo de BSC que se aplique a uma determinada instituição. Vicente et al. (2017), e Coelho (2019) se assemelham ainda mais, por aplicarem também um BSC em um departamento da UFSC.

\section{MATERIAIS E MÉTODOS}

De acordo com o objetivo, este trabalho pode ser caracterizado como de cunho descritivo, pois tem a finalidade de analisar, e verificar, como o desempenho influencia no processo organizacional estudado. As pesquisas descritivas têm como objetivo primordial a descrição das características de determinada população ou fenômeno ou, então, o estabelecimento de relações entre variáveis (GIL, 2008). São inúmeros os estudos que podem ser classificados sob este título e uma de suas características mais significativas estão na utilização de técnicas padronizadas de coleta de dados, tais como o questionário e a observação sistemática, ou seja, é valorizado o contato direto com o ambiente e o evento que está sendo observado (GODOY, 1995).

Assume características de pesquisa exploratória, pois articula o levantamento referencial de trabalhos já produzidos sobre esse tema, com entrevistas com servidores que participam da gestão da instituição, na editora escolhida. Já Beuren (2006, p. 81), diz que "explorar um assunto significa reunir mais conhecimento e incorporar características inéditas, bem como buscar novas dimensões até então não conhecidas". 
Elaboração do Balanced Scorecard alinhado aos objetivos da Universidade Federal de Santa Catarina: Um estudo de caso na Editora da UFSC

A pesquisa bibliográfica também foi utilizada a fim de possibilitar a verificação de fenômenos já estudados integrando-os ao estudo proposto (CERVO; BERVIAN, 2002). Essa pesquisa objetiva-se a impactar informações para capacitar a implementação prática para soluções de equívocos inerentes a editora da instituição de ensino superior, então, conforme a sua natureza tem a modalidade de pesquisa aplicada.

Com relação aos procedimentos técnicos, essa pesquisa caracteriza-se como uma Pesquisa-ação, já que busca intervir em problemas organizacionais da Editora da Universidade Federal de Santa Catarina. Esse tipo de pesquisa possui características situacionais, pois busca diagnosticar um problema específico numa dada situação inerente ao setor e tem por objetivo alcançar resultados práticos e conduzir à alguma ação social, basicamente faz a junção entre pesquisa e ação, cooperando os estudos em situações reais e trazendo soluções (GIL, 2008).

Por fim, quanto ao procedimento de coletas de dados, essa pesquisa baseia-se em dados primários, com troca de informações entre os servidores da administração da editora em estudo. Além disso, baseou-se em dados secundários quanto ao levantamento de trabalhos anteriormente realizados, e outras obra utilizadas para o presente estudo.

A escolha dos dados se deu pela justificativa dos pesquisadores procurar soluções para o seu cotidiano, pois trabalham na UFSC, como também a importância da UFSC no cenário nacional, pois detém considerável confiança social e desenvolve melhorias para o bem-estar social. Para a coleta de dados primários, realizará entrevista com o atual diretor da Editora da UFSC. Esta entrevista será não-estruturada, mas contará com um roteiro com a ordem dos assuntos a serem abordados. Entrevista não estruturada, segundo Lakatos e Marconi (2010) é o tipo de entrevista em que o entrevistador possui maior liberdade para desenvolver um tema que acredite ser mais relevante.

O método de observação participante será utilizado, pois o pesquisador faz parte do quadro de servidores lotados na Editora da UFSC, e a observação é feita na Editora da instituição de ensino superior, em seus processos estratégicos, táticos e operacionais. Segundo esse tipo de observação é onde o pesquisador participa ativamente na comunidade ou grupo, ou seja, Marconi e Lakatos (1999, p. 90) dizem que "[...] utiliza os sentidos na obtenção de determinados aspectos da realidade. Consiste em ver, ouvir e examinar fatos ou fenômenos". O pesquisador participa das atividades normais do qual está estudando. As informações complementares são necessárias, pois são retiradas de documentos, registros administrativos, contábeis e financeiros, a fim de complementações de informações após a coleta dos dados. No Quadro 2 é apresentado o enquadramento metodológico do estudo.

Quadro 2 - Enquadramento Metodológico do Estudo

\begin{tabular}{|c|c|}
\hline Descrição quanto a (aos): & Classificação conforme descrição: \\
\hline Abordagem do Problema & Pesquisa Qualitativa \\
Natureza dos Objetivos & Pesquisa Descritiva \\
Natureza da Pesquisa & Pesquisa Aplicada \\
Procedimentos Técnicos & Pesquisa-ação \\
Coleta de Dados & Dados Primários e Dados Secundários \\
\hline
\end{tabular}

Fonte: dados da Pesquisa (2019).

A escolha da entidade ocorreu devido à amplitude do seu processo produtivo, por prestar serviços na parte educacional, pelo pesquisador fazer parte do seu quadro de funcionários da editora entre os anos de 2018 até 2019, e ter acesso facilitado aos gestores, por isso a pesquisa se desenrolou, aproximadamente, durante um ano. Com o intuito de se obter um recorte literário do tema análise de desempenho em instituições de ensino superior, o instrumento utilizado é chamado de Knowledge Development Process - Construtivist 
(ProKnow-C). Esse instrumento construtivista, constrói e estrutura o conhecimento de forma a explorar o tema abordado na pesquisa, facilitando o processo para o pesquisador (ENSSLIN et al., 2010). Foram pesquisadas as palavras-chave: no eixo 1 'Avaliação de Desempenho' e no eixo 2 'Editoras', como resultado foram obtidas 733 publicações, com o filtro final permanecendo 20 publicações de portfólio da pesquisa. Foi utilizada a base Scopus, pois é uma base de dados confiável e que conta com muitos artigos e autores que têm relevância científica.

As etapas para o desenvolvimento da pesquisa foram da seguinte forma: inicialmente foi realizada entrevista com o diretor, em exercício, da Editora universitária e com os servidores com cargo de chefia com o intuito de coleta de dados. Como também, foi observado documentos, regimentos, regras, relatórios internos e o planejamento estratégico institucional. Constará como desenvolvimento da pesquisa as atividades relacionadas a editora e suas conclusões servirão para atingir os objetivos estratégicos da UFSC.

Para desenvolver o mapa estratégico da editora da instituição de ensino superior é preciso todos os objetivos e metas, estratégicas, que estão incluídas no Plano de Desenvolvimento Institucional e tenham enlace direto com a editora. Esse objetivo será atingido por meio da análise da missão, visão e valores, que constam no PDI 2015/2019, como todas as metas e objetivos.

Figura 2 - Perfil institucional, Objetivos e Metas do Plano de Desenvolvimento Institucional

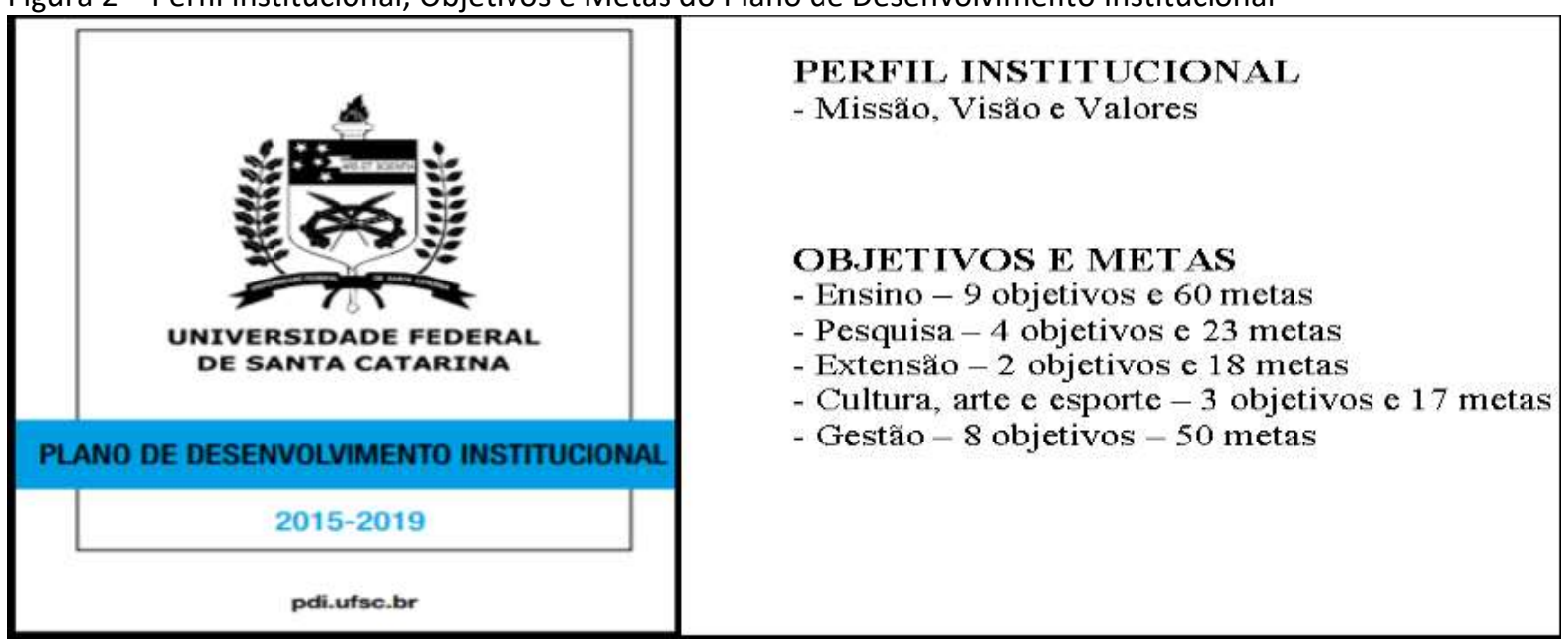

Fonte: dados da Pesquisa (2019).

Cada unidade tem sua função dentro da instituição, e interagem com as demais unidades, na busca de atingir os objetivos estratégicos institucionais, é fato o entendimento do alinhamento institucional. A ideia do BSC nas organizações é capacitar a gestão com foco e alinhamento nas suas unidades, sejam elas negociais, de serviços, de pessoal, financeiro, tecnologia na estratégia organizacional. Esse alinhamento cria melhorias conjuntas no desempenho, conforme se observa na Figura 3 (KAPLAN; NORTON 2000). 
Elaboração do Balanced Scorecard alinhado aos objetivos da Universidade Federal de Santa Catarina: Um estudo de caso na Editora da UFSC

Figura 3 - Estratégicas para elaborar e implementar o BSC

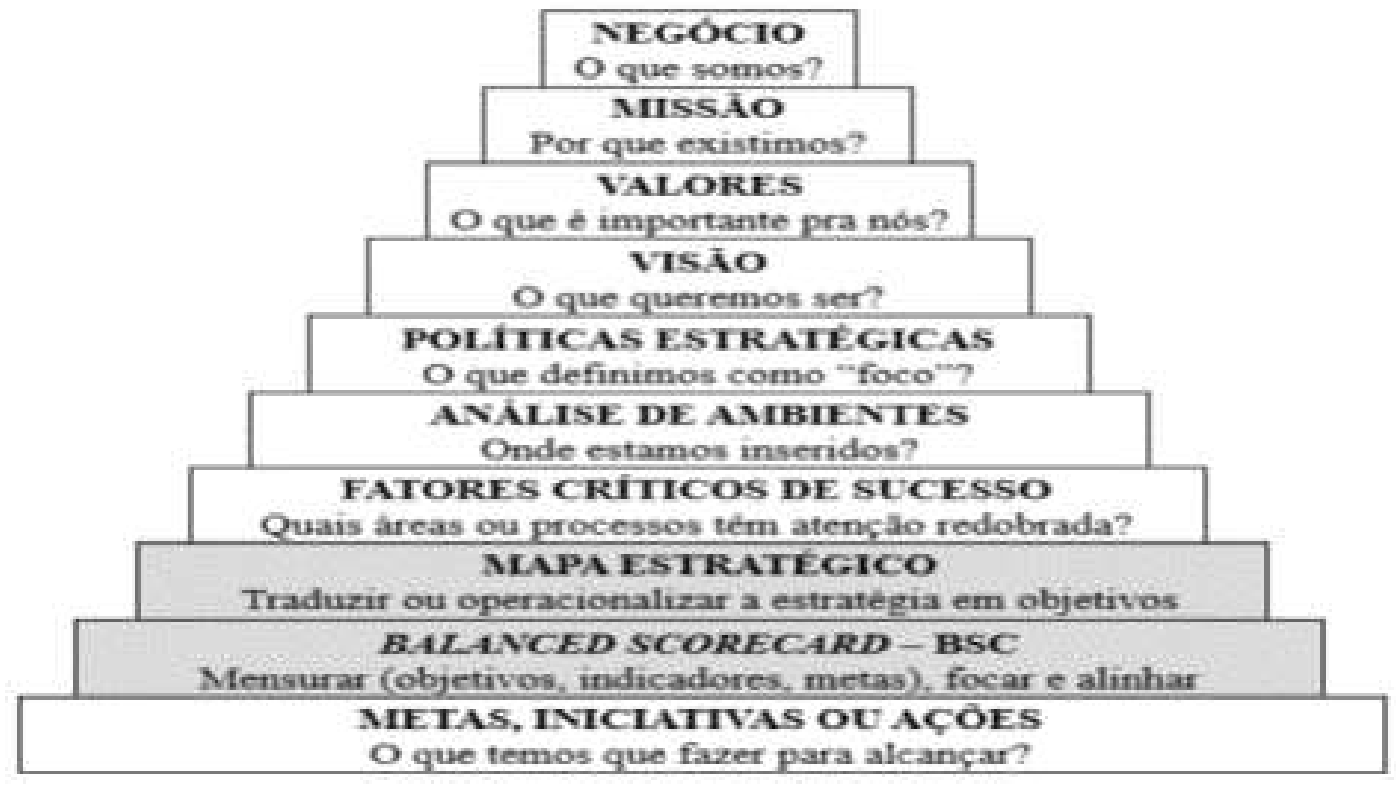

Fonte: transcrito de Kaplan e Norton (2004, p. 35).

Após traduzir ou operacionalizar a estratégia em objetivos, cabe ressaltar que se será executado o painel estratégico, denotando as perspectivas, objetivos, cenário atual, metas, e as ações para atingir as metas é a fase final do BSC. A Figura 4 representa uma estrutura básica do que sobre as perspectivas do BSC, ao qual é necessário a criação de indicadores para busca da performance, se está satisfatório e qual a propulsão futura das perspectivas.

Figura 4 - Demonstração da integração das perspectivas do BSC
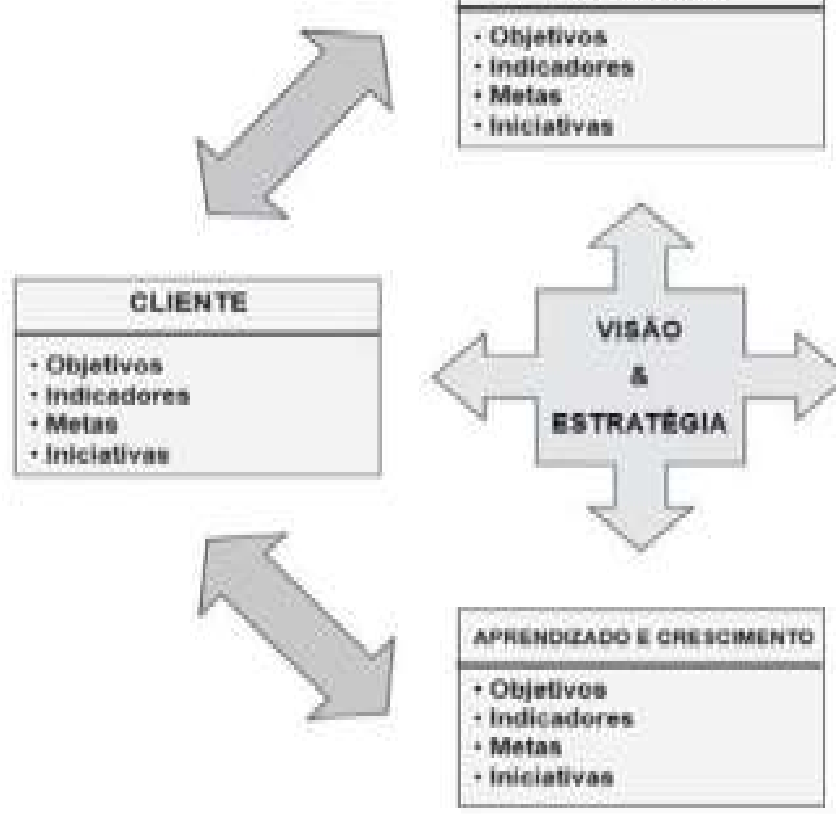

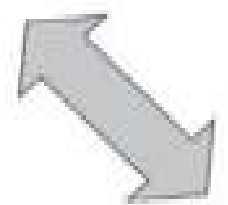

\begin{tabular}{|l|}
\hline PRodrssos inTERMOS \\
\hline - Ohjetivgh \\
- Indicadores \\
- Metas \\
- Inleintivas
\end{tabular}

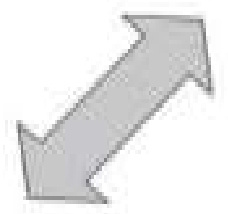

Fonte: transcrito de Kaplan \& Norton (2001, p.70)

Com a verificação das perspectivas da Figura 4 foi elaborado o painel de desempenho do BSC, mediante o que foi proposto por Kaplan e Norton (2000), porém cabe salientar que 
será utilizada o aperfeiçoamento de Petri (2005), que está exposto na Figura 5.

Figura 5 - Aperfeiçoamento da fase de estruturação

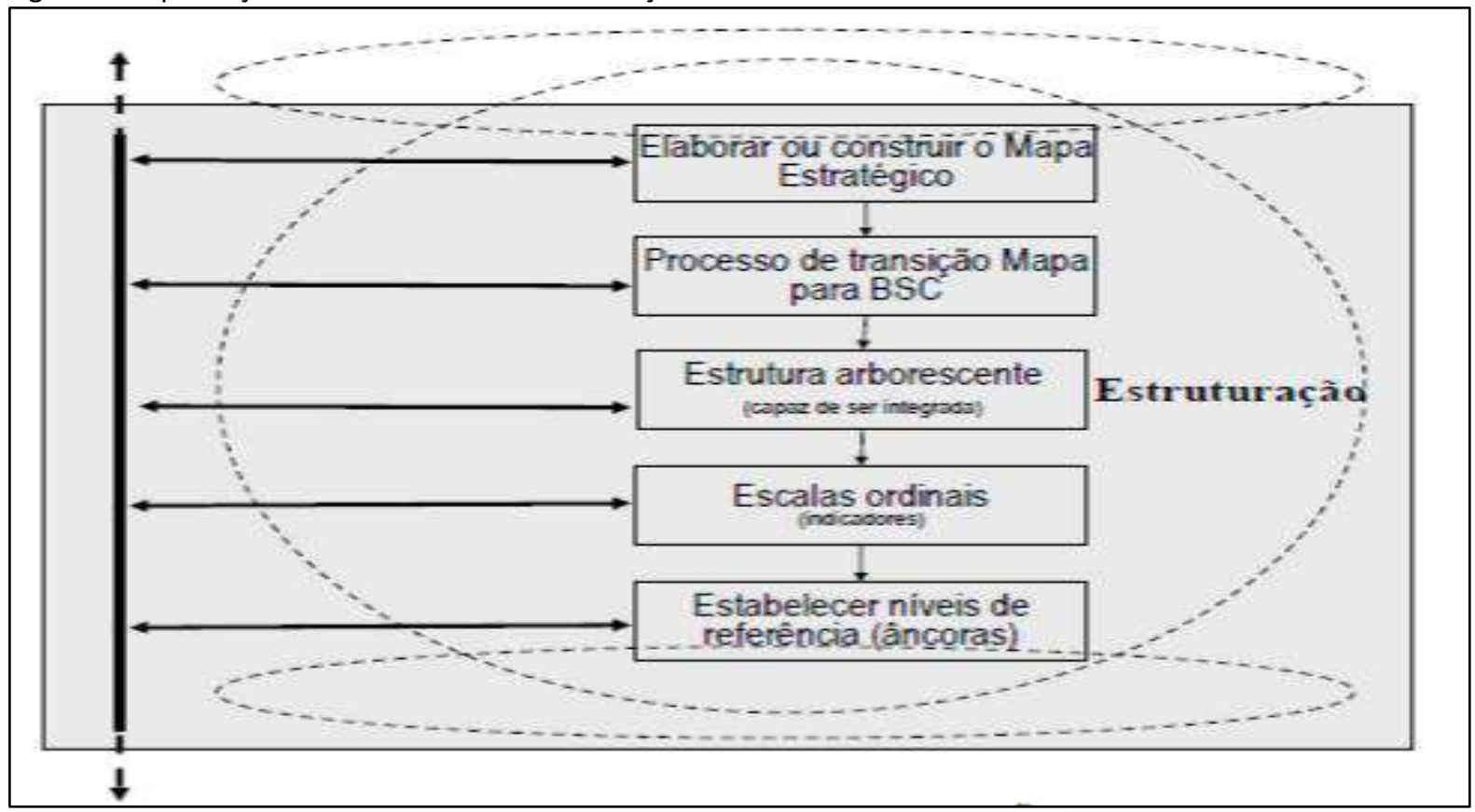

Fonte: Petri (2005, p. 192).

A Figura 5 demonstra que Petri (2005) se estabelece de níveis de referência de cada indicador (máximo e mínimo), desejado, que é definido pela meta estabelecida. Ao qual define-se as escalas ordinais para identificar a integração com a intensão de elaborar ou construir o mapa estratégico da instituição e finalizar o BSC.

\section{RESULTADOS}

Para desenvolver o mapa estratégico da editora da instituição de ensino superior é preciso envolver todos os objetivos e metas estratégicas que estão incluídas no Plano de Desenvolvimento Institucional e tenham enlace direto com a Editora (Figura 2). Esse objetivo será atingido por meio da análise da missão, visão e valores, que constam no PDI 2015-2019, assim como todas as metas e objetivos.

O PDI 2015/2019 define os objetivos e metas a serem alcançados em cinco dimensões: 1) ensino; 2) pesquisa; 3) extensão; 4) cultura, arte e esportes; e 5) gestão. Sua finalidade é constar como peça fundamental para o planejamento estratégico da Universidade Federal de Santa Catarina em projeções de curto prazo, em que são definidas as suas bases estratégicas. 
Elaboração do Balanced Scorecard alinhado aos objetivos da Universidade Federal de Santa Catarina: Um estudo de caso na Editora da UFSC

Figura 6 - Mapa Estratégico da EdUFSC e Integração com a Estratégia Institucional

\begin{tabular}{|c|c|c|c|c|}
\hline \multirow[t]{2}{*}{ APRENDIZADO E CRESCIMENTO } & \multirow[t]{2}{*}{\begin{tabular}{|c|} 
PROCESSOS \\
INTERNOS \\
\end{tabular}} & \multirow{2}{*}{$\begin{array}{l}\text { CLIENTES } \\
\text { INTERNO } \\
\end{array}$} & \multirow[t]{2}{*}{$\begin{array}{c}\text { MISSÃO DA EDITORA } \\
\text { DA UFSC } \\
\end{array}$} & \multirow[t]{2}{*}{ MISSÃO DA UFSC } \\
\hline & & & & \\
\hline \multirow[t]{2}{*}{$\begin{array}{c}\text { Contratar e capacitar } \\
\text { bolsistas/estagiários afim de atuar na } \\
\text { EdUFSC, assim como auxiliar o seu } \\
\text { desenvolvimento profissional }\end{array}$} & \multirow{7}{*}{$\begin{array}{c}\text { Aprimorar } \\
\text { tecnologias } \\
\text { que possam } \\
\text { reduzir } \\
\text { custos, } \\
\text { otimizar o } \\
\text { tempo, } \\
\text { estabelecer } \\
\text { procediment } \\
\text { os padrões e } \\
\text { mitigar o } \\
\text { risco nos } \\
\text { processos }\end{array}$} & $\begin{array}{c}\text { Sustentar a produção de títulos } \\
\text { que sejam aprovados pelo } \\
\text { conselho editorial e que tenham } \\
\text { qualidade. }\end{array}$ & \multirow{7}{*}{\begin{tabular}{|c|} 
Ser uma Editora \\
Universitária que \\
atende a demanda \\
técnico-científica e \\
acadêmica da UFSC, \\
assim como da \\
comunidade em \\
geral. E, além disso, \\
contribuir com a \\
disseminação do \\
conhecimento, por \\
meio da publicação \\
de obras com \\
excelência técnica \\
quanto aos aspectos \\
de revisão, \\
editoração e \\
impressão, com \\
preços de capa \\
acessíveis aos \\
estudantes e ao \\
público em geral, \\
cumprindo assim sua \\
função social \\
enquanto editora de \\
uma universidade \\
pública federal. \\
\end{tabular}} & \multirow{7}{*}{\begin{tabular}{|c|} 
A UFSC tem por \\
missão \\
"produzir, \\
sistematizar e \\
socializar o \\
saber filosófico, \\
científico, \\
artístico e \\
tecnológico, \\
ampliando e \\
aprofundando a \\
formação do ser \\
humano para o \\
exercício \\
profissional, a \\
reflexão crítica, a \\
solidariedade \\
nacional e \\
internacional, na \\
perspectiva da \\
construção de \\
uma sociedade \\
justa e \\
democrática e \\
na defesa da \\
qualidade da \\
vida". \\
\end{tabular}} \\
\hline & & $\begin{array}{c}\text { Resguardo das obras publicadas } \\
\text { pela EdUFSC } \\
\end{array}$ & & \\
\hline \multirow[t]{2}{*}{$\begin{array}{c}\text { Incentivar a participação de servidores } \\
\text { em eventos, congressos ou encontros } \\
\text { acadêmicos, assim como cursos. }\end{array}$} & & $\begin{array}{l}\text { Incentivar o acesso à informação, } \\
\text { proporcionando conhecimento } \\
\text { mediante ao material informativo }\end{array}$ & & \\
\hline & & EXTERNO & & \\
\hline $\begin{array}{c}\text { Proporcionar a integração das } \\
\text { informações produzidas pelos } \\
\text { servidores da UFSC com o público em } \\
\text { geral }\end{array}$ & & $\begin{array}{c}\text { Divulgar informações sobre as } \\
\text { publicações feitas com o selo da } \\
\text { EdUFSC que melhorem a } \\
\text { compreensão sobre a literatura, } \\
\text { cultura, didática e científica } \\
\end{array}$ & & \\
\hline \multirow[b]{2}{*}{$\begin{array}{c}\text { Capacitação dos servidores para que } \\
\text { utilizem o sistema }\end{array}$} & & $\begin{array}{c}\text { Divulgações de informações } \\
\text { pertinentes aos projetos } \\
\text { desenvolvidos pela UFSC } \\
\end{array}$ & & \\
\hline & & $\begin{array}{c}\text { Obter retorno da qualidades das } \\
\text { obras produzidas por recebimento } \\
\text { de prêmios mediante participação } \\
\text { em eventos para fortalecer o selo } \\
\text { da EdUFSC no cenário nacional }\end{array}$ & & \\
\hline
\end{tabular}

Fonte: dados da Pesquisa (2019).

Para desenvolver o painel de desempenho do BSC é necessário fazer a transição do mapa estratégico, informando as perspectivas, os objetivos, os indicadores, de onde se captou a informação e a sua cronologia, conforme indicado no Quadro 3.

Quadro 3 - Mapa Estratégico da Editora da UFSC

\begin{tabular}{|c|c|c|c|c|c|c|c|c|}
\hline \multirow{2}{*}{ 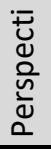 } & \multirow[b]{2}{*}{ Objetivos } & \multirow[b]{2}{*}{ Indicador } & \multicolumn{2}{|c|}{ Referência } & \multirow{2}{*}{$\begin{array}{c}\text { Status } \\
\text { Quo }\end{array}$} & \multirow{2}{*}{$\begin{array}{c}\text { Descrição das } \\
\text { Metas }\end{array}$} & \multirow{2}{*}{$\begin{array}{l}\text { Score } \\
\text { Meta }\end{array}$} & \multirow[b]{2}{*}{ Iniciativas } \\
\hline & & & Sup. & Inf. & & & & \\
\hline \multirow{3}{*}{ 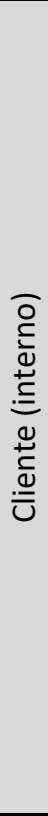 } & $\begin{array}{c}\text { Sustentar a } \\
\text { produção de títulos } \\
\text { que sejam } \\
\text { aprovados pelo } \\
\text { conselho editorial e } \\
\text { que tenham } \\
\text { qualidade. }\end{array}$ & $\begin{array}{l}\% \text { de obras } \\
\text { produzidas no } \\
\text { decorrer das } \\
\text { atividades da } \\
\text { editora }\end{array}$ & $80 \%$ & $25 \%$ & -6 & $\begin{array}{c}\text { Avaliar } 75 \% \text { das } \\
\text { obras } \\
\text { encaminhadas } \\
\text { para a Editora }\end{array}$ & 91 & $\begin{array}{l}\text { Realizar } \\
\text { reuniões com } \\
\text { possíveis } \\
\text { autores antes } \\
\text { do primeiro } \\
\text { envio }\end{array}$ \\
\hline & $\begin{array}{c}\text { Resguardo das obras } \\
\text { publicadas pela } \\
\text { EdUFSC }\end{array}$ & $\begin{array}{l}\% \text { de obras } \\
\text { reservadas em } \\
\text { relação as } \\
\text { produzidas }\end{array}$ & $\begin{array}{c}100 \\
\%\end{array}$ & $80 \%$ & 17 & $\begin{array}{l}\text { Implantar o } \\
\text { controle de } \\
100 \% \text { na } \\
\text { reserva técnica }\end{array}$ & 100 & $\begin{array}{c}\text { Fazer o } \\
\text { inventário da RT } \\
\text { e o } \\
\text { tombamento na } \\
\text { UFSC }\end{array}$ \\
\hline & $\begin{array}{c}\text { Incentivar o acesso à } \\
\text { informação, } \\
\text { proporcionando } \\
\text { conhecimento } \\
\text { mediante ao } \\
\text { material } \\
\text { informativo. }\end{array}$ & $\begin{array}{l}\text { \% de material } \\
\text { desenvolvido } \\
\text { para os } \\
\text { servidores, } \\
\text { docente e } \\
\text { discente. }\end{array}$ & $80 \%$ & $25 \%$ & 6 & $\begin{array}{c}\text { Ampliar a } \\
\text { divulgação } \\
\text { para } 75 \% \text { de } \\
\text { material } \\
\text { voltado ao } \\
\text { público interno } \\
\text { da UFSC } \\
\end{array}$ & 91 & $\begin{array}{l}\text { Impulsionar as } \\
\text { informações por } \\
\text { meio de redes } \\
\text { sociais, } \\
\text { acadêmicas e } \\
\text { profissionais. }\end{array}$ \\
\hline 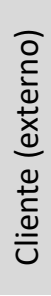 & $\begin{array}{c}\text { Divulgar } \\
\text { informações sobre } \\
\text { as publicações feitas } \\
\text { com o selo da } \\
\text { EdUFSC que } \\
\text { melhorem a } \\
\text { compreensão sobre }\end{array}$ & $\begin{array}{c}\% \text { de } \\
\text { informativos } \\
\text { confeccionados } \\
\text { para o site da } \\
\text { livraria e } \\
\text { editora }\end{array}$ & $70 \%$ & $40 \%$ & -5 & $\begin{array}{l}\text { Alcançar para } \\
60 \% \text { os } \\
\text { informativos } \\
\text { no prazo dos } \\
\text { eventos que a } \\
\text { editora lança } \\
\text { ou participa }\end{array}$ & 67 & $\begin{array}{c}\text { Designar } \\
\text { servidores para } \\
\text { monitorar os } \\
\text { eventos e } \\
\text { planejamento } \\
\text { antecipado. }\end{array}$ \\
\hline
\end{tabular}




\begin{tabular}{|c|c|c|c|c|c|c|c|c|}
\hline \multicolumn{9}{|c|}{$\begin{array}{l}\text { a literatura, cultura, } \\
\text { didática e científica }\end{array}$} \\
\hline & $\begin{array}{c}\text { Divulgações de } \\
\text { informações } \\
\text { pertinentes aos } \\
\text { projetos } \\
\text { desenvolvidos pela } \\
\text { UFSC } \\
\end{array}$ & $\begin{array}{c}\% \text { de } \\
\text { aquisições de } \\
\text { exemplares } \\
\text { novos da } \\
\text { editora }\end{array}$ & $60 \%$ & $10 \%$ & -14 & $\begin{array}{l}\text { Comercializar } \\
50 \% \text { da } \\
\text { produção de } \\
\text { novos } \\
\text { exemplares em } \\
\text { até } 1 \text { ano. } \\
\end{array}$ & 80 & $\begin{array}{c}\text { Divulgar por } \\
\text { diversos canais } \\
\text { os lançamentos } \\
\text { de produção } \\
\text { editorial. }\end{array}$ \\
\hline & $\begin{array}{l}\text { Obter retorno da } \\
\text { qualidade das obras } \\
\text { produzidas por } \\
\text { recebimento de } \\
\text { prêmios mediante } \\
\text { participação em } \\
\text { eventos para } \\
\text { fortalecer o selo da } \\
\text { EdUFSC no cenário } \\
\text { nacional }\end{array}$ & $\begin{array}{l}\% \text { de prêmios } \\
\text { recebidos em } \\
\text { eventos da } \\
\text { área editorial }\end{array}$ & $25 \%$ & $5 \%$ & -25 & $\begin{array}{l}\text { Alcançar para } \\
20 \% \text { os } \\
\text { prêmios de } \\
\text { participações } \\
\text { em eventos } \\
\text { com o Selo da } \\
\text { EdUFSC }\end{array}$ & 75 & $\begin{array}{l}\text { Incentivar a } \\
\text { participação da } \\
\text { EdUFSC em } \\
\text { eventos que } \\
\text { tenham } \\
\text { premiações e } \\
\text { reconhecimento } \\
\text { nacional. }\end{array}$ \\
\hline \multirow{2}{*}{ 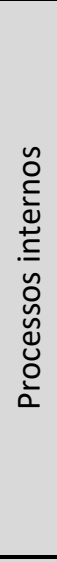 } & \multirow{2}{*}{$\begin{array}{c}\text { Aprimorar } \\
\text { tecnologias que } \\
\text { possam reduzir } \\
\text { custos, otimizar o } \\
\text { tempo, estabelecer } \\
\text { procedimentos } \\
\text { padrões e mitigar o } \\
\text { risco nos processos }\end{array}$} & $\begin{array}{c}\% \text { de processos } \\
\text { devolvidos }\end{array}$ & $20 \%$ & $80 \%$ & 2 & $\begin{array}{c}\text { Diminuir para } \\
30 \% \text { o trâmite } \\
\text { de processos } \\
\text { ineficientes }\end{array}$ & 83 & $\begin{array}{l}\text { Instituir um } \\
\text { manual de } \\
\text { procedimentos } \\
\text { para a EdUFSC } \\
\text { sobre os } \\
\text { trâmites de } \\
\text { mensagens. }\end{array}$ \\
\hline & & $\begin{array}{c}\% \text { de Rotinas e } \\
\text { manuais } \\
\text { desenvolvidos } \\
\text { pela Editora }\end{array}$ & $\begin{array}{c}100 \\
\%\end{array}$ & $50 \%$ & -20 & $\begin{array}{c}\text { Aumentar para } \\
100 \% \text { a } \\
\text { padronização } \\
\text { dos } \\
\text { procedimentos }\end{array}$ & 100 & $\begin{array}{l}\text { Criar um manual } \\
\text { de rotinas que } \\
\text { contemplem } \\
\text { todas as rotinas } \\
\text { e tarefas } \\
\text { internas. } \\
\end{array}$ \\
\hline \multirow{3}{*}{ 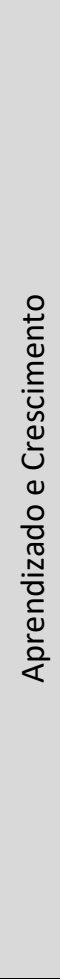 } & $\begin{array}{c}\text { Contratar e } \\
\text { capacitar } \\
\text { bolsistas/estagiários } \\
\text {, a fim de, atuar na } \\
\text { EdUFSC, assim como } \\
\text { auxiliar o seu } \\
\text { desenvolvimento } \\
\text { profissional }\end{array}$ & $\begin{array}{c}\% \text { de vagas de } \\
\text { estágio } \\
\text { ocupadas }\end{array}$ & $\begin{array}{c}100 \\
\%\end{array}$ & $70 \%$ & 17 & $\begin{array}{c}\text { Obter o } \\
\text { percentual de } \\
100 \% \text { das vagas } \\
\text { preenchidas } \\
\text { com bolsistas }\end{array}$ & 100 & $\begin{array}{l}\text { Realizar ações } \\
\text { com a secretaria } \\
\text { de cursos de } \\
\text { graduação e pós } \\
\text { que atendam a } \\
\text { demanda da } \\
\text { EdUFSC. }\end{array}$ \\
\hline & $\begin{array}{c}\text { Incentivar a } \\
\text { participação de } \\
\text { servidores em } \\
\text { eventos, congressos } \\
\text { ou encontros } \\
\text { acadêmicos, assim } \\
\text { como cursos. }\end{array}$ & $\begin{array}{c}\% \text { de } \\
\text { servidores } \\
\text { inscritos para } \\
\text { participar de } \\
\text { eventos }\end{array}$ & $75 \%$ & $50 \%$ & -33 & $\begin{array}{l}\text { Alcançar o } \\
\text { percentual de } \\
70 \% \text { dos } \\
\text { servidores } \\
\text { participantes } \\
\text { em eventos }\end{array}$ & 80 & $\begin{array}{c}\text { Incentivar a } \\
\text { participação de } \\
\text { servidores em } \\
\text { eventos } \\
\text { acadêmicos } \\
\text { inovem os } \\
\text { processos } \\
\text { internos. } \\
\end{array}$ \\
\hline & $\begin{array}{c}\text { Proporcionar a } \\
\text { integração das } \\
\text { informações } \\
\text { produzidas pelos } \\
\text { servidores da UFSC } \\
\text { com o público em } \\
\text { geral }\end{array}$ & $\begin{array}{c}\% \text { de } \\
\text { servidores que } \\
\text { participaram } \\
\text { de cursos } \\
\text { proporcionado } \\
\text { s por outros } \\
\text { setores }\end{array}$ & $70 \%$ & $40 \%$ & -22 & $\begin{array}{l}\text { Almejar que } \\
50 \% \text { dos tenha } \\
\text { aprimorament } \\
\text { o por cursos da } \\
\text { UFSC }\end{array}$ & 33 & $\begin{array}{c}\text { Realizar } \\
\text { treinamentos } \\
\text { com servidores } \\
\text { que aprimorem } \\
\text { as suas aptidões } \\
\text { profissionais. }\end{array}$ \\
\hline
\end{tabular}


Elaboração do Balanced Scorecard alinhado aos objetivos da Universidade Federal de Santa Catarina: Um estudo de caso na Editora da UFSC

\begin{tabular}{|c|c|c|c|c|c|c|c|}
\hline \multirow[b]{2}{*}{$\begin{array}{l}\text { Capacitação dos } \\
\text { servidores para que } \\
\text { utilizem o sistema }\end{array}$} & $\begin{array}{c}\% \text { de } \\
\text { servidores } \\
\text { habilitados } \\
\text { com acesso aos } \\
\text { sistemas }\end{array}$ & $\begin{array}{c}100 \\
\%\end{array}$ & $25 \%$ & 0 & $\begin{array}{l}\text { Projetar o } \\
\text { percentual de } \\
100 \% \text { de } \\
\text { acesso a } \\
\text { sistemas }\end{array}$ & 100 & $\begin{array}{c}\text { Realizar } \\
\text { habilitação de } \\
\text { servidores aos } \\
\text { sistemas } \\
\text { utilizados na } \\
\text { EDUFSC. }\end{array}$ \\
\hline & $\begin{array}{c}\% \text { de } \\
\text { servidores } \\
\text { capacitados e } \\
\text { que tem acesso } \\
\text { ao sistema }\end{array}$ & $\begin{array}{c}100 \\
\%\end{array}$ & $25 \%$ & -22 & $\begin{array}{c}\text { Alcançar } 100 \% \\
\text { de capacitados } \\
\text { e com acesso } \\
\text { aos sistemas }\end{array}$ & 100 & $\begin{array}{c}\text { Efetuar } \\
\text { treinamentos } \\
\text { para que os } \\
\text { servidores } \\
\text { estejam } \\
\text { capacitados a } \\
\text { efetuar as suas } \\
\text { rotinas diárias. }\end{array}$ \\
\hline
\end{tabular}

Fonte: dados da Pesquisa (2019).

Com relação a esse refinamento, da etapa de avaliação, é desenvolvido o modelo global de avaliação de desempenho com uma taxa de compensação, com a intenção de traduzir em informações sintetizadas sobre a Avaliação Global da EdUFSC.

A avaliação global do desempenho da Editora da UFSC é demonstrada, na Tabela 1, que apresenta a pontuação global, visualizando que a pontuação do cenário atual é negativa em 8 pontos e, após a atribuição das metas, o desempenho ficou positivo em 86 pontos.

Tabela 1 - Avaliação Global do desempenho da EdUFSC

\begin{tabular}{c|c|c|c}
\hline Perspectiva & Taxa & Pontuação Status Quo & Meta \\
\hline Cliente (Interno) & $25,00 \%$ & 6 & 94 \\
Cliente (Externo) & $25,00 \%$ & -15 & 74 \\
Processos Internos & $25,00 \%$ & -9 & 91,5 \\
Aprendizado E Crescimento & $25,00 \%$ & -12 & $\mathbf{8 2 , 6}$ \\
Avaliação Global & $\mathbf{1 0 0 , 0 0 \%}$ & $\mathbf{- 8}$ & $\mathbf{8 6}$ \\
\hline
\end{tabular}

Fonte: dados da Pesquisa (2019).

Com a representação gráfica apresentada na Figura 2 para o modelo proposto, fica evidente a melhoria provocada pela atribuição das metas. Essa forma de apresentação facilita a interpretação das informações sobre a Editora da UFSC com relação a cada um dos 13 indicadores selecionados.

Figura 7 - Perfil Gráfico do Desempenho da EdUFSC

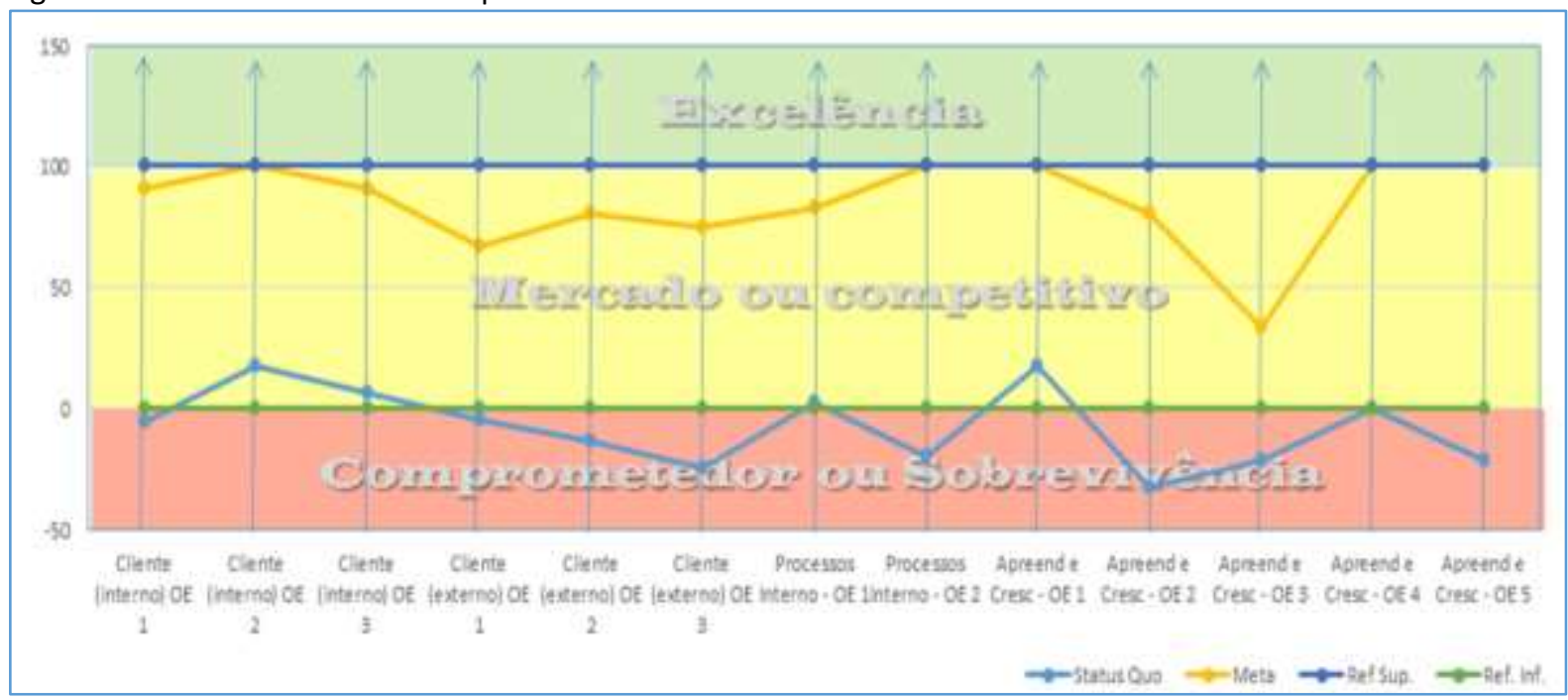

Fonte: dados da Pesquisa (2019). 
Quando se observa a situação atual da editora é sensato dizer que não existe um indicador de excelência, e apenas os Indicadores da perspectiva Clientes (interno) C2 Resguardo das obras publicadas pela EdUFSC; Clientes (interno) C3 - Incentivar o acesso à informação, proporcionando conhecimento mediante ao material informativo; Processos internos - PI 1 - Aprimorar tecnologias que possam reduzir custos, otimizar o tempo, estabelecer procedimentos padrões e mitigar o risco nos processos; Aprendizado e Crescimento - AC 1 - Contratar e capacitar bolsistas/estagiários, a fim de, atuar na EdUFSC, assim como auxiliar o seu desenvolvimento profissional, tem características de mercado ou competitivos. Os restantes dos indicadores estão no nível comprometedor ou de sobrevivência.

Respondendo a questão problema da pesquisa que é "Quais indicadores estão alinhados a estratégia, de comercialização/autossustentação, para gerenciamento da Editora da Universidade Federal de Santa Catarina?", o estudo trouxe o fundamento científico para a identificação e alinhamento da Editora à estratégia institucional da UFSC, expôs mapa estratégico e painel de desempenho por BSC que definiu quais os indicadores que estão alinhados a estratégia, assim como propôs ações a iniciativas que aprimorem a gestão e a sua influência na análise gráfica e melhoraram a avaliação global, pelo método escolhido.

Como limitador do estudo aborda-se a pouca literatura direcionada para editoras universitárias, a fim de ter comparabilidade das informações e a possibilidade de não aplicação do estudo por parte da gestão pode limitar o estudo a ser apenas teórico, e não possibilitando as contribuições do método na prática organizacional.

É importante salientar que o processo do estudo foi contribuinte, também, para a criação de metas, verificação de objetivos e auxílio no desenvolvimento no PDI UFSC (20202024), no que tange a Editora da UFSC. O ponto crítico continua sendo a falta de emissão de nota fiscal para legalizar o processo de comercialização e, futura, responsabilização sobre os estoques após estar incorporado, contabilmente, ao patrimônio da UFSC.

A abrangência de pesquisas sobre avaliação de desempenho integra possibilidades distintas, porém, como lacuna de pesquisa pode-se fazer o estudo em outra editora universitária, com as mesmas características e fazer a comparabilidade das informações colhidas, indicando se apresenta melhora na gestão com a aplicação do método BSC, assim como avaliar todos os pontos semelhantes sobre os objetos de estudos. Ou instituir modelos distintos para avaliação de desempenho de instituições públicas de ensino e observar orientações que melhorem a gestão das instituições. Como também, verificar a percepção dos gestores dessas instituições sobre o que pode contribuir com a gestão se for implementado o modelo BSC, ou verificar se alguma instituição já aplicou o BSC e quais os reflexos práticos.

\section{ANÁLISES DOS RESULTADOS}

No presente estudo, sobre a análise de desempenho por meio do instrumento BSC, é importante ressaltar os resultados obtidos nesse estudo, como também, e trazer a discussão para o cunho acadêmico, e científico, com autores que possam contribuir com as informações colhidas nessa pesquisa e enriquecer a análise dos resultados, ao qual se fará o enlace nesse tópico 4.2 .

A proposta do estudo tem como objetivo confeccionar a avaliação de desempenho da Editora da Universidade Federal de Santa Catarina, partindo da ideia sobre o alinhamento estratégico com o PDI UFSC (2015-2019), verificando por meio as atividades desenvolvidas no cotidiano da editora influenciam no êxito da estratégia global da UFSC. Esse alinhamento estratégico é afirmado por Kaplan e Norton (1993) na concepção do método BSC, como 
Elaboração do Balanced Scorecard alinhado aos objetivos da Universidade Federal de Santa Catarina: Um estudo de caso na Editora da UFSC

também foi corroborado pelos estudos de Taylor e Banes (2012) e Kettunen (2008) quando apontam que deve ser refletida a missão, o planejamento estratégico, e os processos existentes na instituição por meio da aplicação do BSC, e que o alinhamento deve ser desenvolvido, e válido, com a intensão de atingir os objetivos estratégicos, apoiando e dando vigor a sua diligência.

O caminho é o meio para se chegar às concepções de medidas de desempenho e obter as interações entre as formulações das estratégias institucionais, conforme Szabo e Sidor (2014), e seus resultados advém de observações críticas sobre a estratégia. Por isso, o mapa estratégico foi criado para estabelecer o alinhamento da estratégia da Editora com a estratégia institucional do PDI UFSC (2015-2019), ou seja, foi observado que alguns objetivos e metas tem alinhamento institucional e o mapa foi configurado por meio dessas informações.

Esse caminho continuou sendo descrito pela apresentação do Painel de Desempenho do BSC da Editora da UFSC, que norteiam os objetivos, indicadores, metas e ações, obtendo clareza das informações sobre os objetivos estratégicos da Editora, direcionando o monitoramento de cada objetivo instaurado, como também, o que pode ser alcançado e quais ações que podem ser providenciadas para alcanças esses níveis propostos. Isso corrobora com a ideia de Boland e Fowler (2000), no contexto de avaliação de desempenho de instituição pública, pois retratam o exame, e/ou uma discussão, sobre a medição de desempenho, indicadores de desempenho e iniciativas de melhoria associadas, aplicadas em organizações do setor público.

Prosseguindo com o ensejo, então, quando se apresentou o Painel de Desempenho Refinado, a Avaliação Global do Desempenho e a configuração gráfica da Editora da UFSC, se podem visualizar, em relação ao cenário atual, que se forem tomadas como base as ações ou iniciativas previstas, nesse estudo, qual seria a repercussão em cada meta proposta. Essa construção é refletida, também, na ideia de Radnor e Mcguire (2004), quando reflete sobre o painel de produtividade dos serviços públicos e tenta responder sobre avaliação de desempenho, ou seja, produz o entendimento da possibilidade de aumento de produtividade e o desempenho em organizações públicas.

Em se pensando em estratégia institucional global, cada indivíduo que participa das atividades cotidianas da organização é contribuinte para o sucesso dessa estratégia, e participa do aprimoramento dos modelos a desenvolvidos na organização. Corroborando os estudos de Jamshidnezhad e Barherzadeh (2017), o indicador que está ligado ao colaborador, que pratica as atividades cotidianas, torna-se peça fundamental para atingir os objetivos e metas da instituição, ou seja, é um indicador da avaliação de desempenho que precisa ser observado com maior sensibilidade. Essa afirmativa também se alinha aos estudos Papenhausen e Einstein (2006) que informa que os colaboradores de universidades necessitam entender a estratégia institucional para influenciar na evolução dos resultados.

Os resultados obtidos nos estudos de Philbin (2011), quando identifica como a gestão universitária pode ser melhorada por meio da adoção de um sistema integrado de mensuração de desempenho baseado no Balanced Scorecard, ampara a presente pesquisa na sustentação de que o método BSC apoia o aprimoramento da estratégia organizacional, assim como Kettunen (2008), contribui e, aborda que o BSC expõe as informações estratégicas para a clareza da compreensão, assim como efetiva o planejamento estratégico organizacional. 0 presente estudo corrobora também com Papenhausen e Einstein (2006) e Chen, Wang e Yang (2009) quando ressalta que a abordagem do Balanced Scorecard é bem adequada a uma situação de ensino superior e permite o alinhamento de uma ampla variedade de medidas 
com a missão e a estratégia única, assim como pode ser entendida como um instrumento de autoavaliação para alvejar o objetivo de gestão de desempenho.

Justificam-se as medidas de desempenho mediante a escolha dos indicadores acolhidos nesse estudo, e corroborando com o estudo de Ismail e Al-Thaoiehie (2015) sobre a importância da opinião dos colaboradores das universidades, sobre os principais indicadores, e esses derivam de adaptações das dimensões do modelo de BSC proposto por Kaplan e Norton (1992). Ou seja, no presente estudo as informações colhidas foram debatidas por servidores em cargo de chefia, ou direção, da editora da UFSC com o intuito de aprimorar a gestão estratégica com o alinhamento ao PDI UFSC (2015-2019), validando as informações como confiáveis para o desenvolvimento do estudo. A participação do autor do estudo e ao mesmo tempo servidor da EdUFSC, tem a intensão de ser imparcial, e impessoal, porém pode ser entendido como benéfico por Chen, Yang e Shiau (2006), para a instituição quando o servidor entende as necessidades do setor ao qual é verificado. O entendimento do colaborador sobre o questionário e essa percepção foca na estratégia da UFSC, então a sua compreensão com as suas atividades cotidianas se alinham com os objetivos e metas do PDI UFSC (2015-2019) e é parte primordial ao desenvolvimento da pesquisa.

Sobre os resultados, considerados relevantes, da aplicação do BSC em uma editora universitária inserida na UFSC é importante relatar o que foi apresentado na Tabela 1, que fala sobre a avaliação global do BSC, o seu cenário sai de um desempenho negativo para uma média da meta de oitenta e seis pontos positivos, e é perceptível que todas as perspectivas se empoderam e evoluem positivamente. Observando o comportamento gráfico do desempenho, na Figura 1, a performance para os indicadores, anterior as iniciativas, era de estar mais próximo da faixa avermelhada, de comprometedor ou sobrevivência, informando que o cenário é temerário na maioria dos indicadores. Após a aplicação das ações e iniciativas, propostas pelo método BSC, a linha no perfil gráfico, na Figura 1, subiu em todos os indicadores para mercado ou competitivo, e alguns dos índices permeiam a excelência, se tomadas às providências necessárias, e de ser apreciado o aumento do nível na Avaliação Global do Desempenho da EdUFSC, conforme a Tabela 1.

Com a apresentação dos resultados desta pesquisa, nota-se por meio de uma comparação e avaliação com os achados de Coelho (2019) e Silveira (2019), que também têm o foco na aplicabilidade do BSC em instituições de ensino superior público, os seus resultados influenciam, também, para a aplicabilidade ou implementação o modelo BSC, em que todos os estudos direcionam para um reflexo positivo nas perspectivas sugeridas, contribuindo com o alinhamento com a gestão estratégica institucional.

Os resultados apresentados e discutidos neste estudo fundamentam, argumentam e lastreiam a proposição da aplicação do modelo de avaliação de desempenho por meio da ferramenta Balanced Scorecard, instruindo a gestão para desenvolver ações e iniciativas que direcionem para a elevação do nível dos indicadores, em meio a tornar eficiente o aprimoramento da gestão estratégica institucional da Editora da UFSC, com abordagem genuína com alinhamento com o PDI UFSC (2015-2019).

\section{CONSIDERAÇÕES FINAIS}

O estudo parte dos pressupostos de Kaplan e Norton (1992) que direcionam o alinhamento estratégico como fator valioso para a construção do sucesso da instituição, principalmente quando desenvolvidos pela ferramenta BSC, onde foi realizada a avaliação de desempenho da Editora da Universidade Federal de Santa Catarina. 
Elaboração do Balanced Scorecard alinhado aos objetivos da Universidade Federal de Santa Catarina: Um estudo de caso na Editora da UFSC

Com o intuito de contemplar a proposta do objetivo geral da pesquisa que é "Propor um modelo de painel de desempenho, pelo instrumento Balanced Scorecard, para a Editora da Universidade Federal de Santa Catarina com medidas alinhadas a estratégia da instituição/abertura de mercado". Constata-se que para atender o objetivo geral da pesquisa foi necessário estabelecer subdivisões específicas do objetivo e ponderar o desenvolvimento de cada subdivisão para alcançá-los, que são: i) operacionalizar a estratégia da Editora da Universidade Federal de Santa Catarina; ii) integrar o PDI da UFSC com os objetivos estratégicos da Editora da Universidade Federal de Santa Catarina; e iii) elaborar o painel de Desempenho da Editora da Universidade Federal de Santa Catarina.

O desenvolvimento da pesquisa e alcance dos objetivos geral e específico se dá, inicialmente, pela verificação da base estratégica das instituições observada na Figura 1. Em seguida, foi necessária análise ambiental que ressaltasse condições internas, e externas, importantes sobre a identificação de fatores de força, fraquezas, oportunidades e ameaças. Por meio de interações com os chefes de setores e com o diretor sobre o Plano de Desenvolvimento Institucional da UFSC (2015-2019) ao qual ficou acordado quais objetivos são relacionados diretamente com a estratégia da EdUFSC. Com a definição dos objetivos alinhados ao plano institucional foram apresentadas as metas inseridas em cada objetivo, e torna-se a visualização do desenho estratégico por meio da criação do Mapa Estratégico da EdUFSC integrado ao PDI UFSC (2015-2019), com a apresentação da Figura 2. Foram ainda estabelecidos os indicadores que integram o Mapa Estratégico da EdUFSC (Quadro 3), que são necessários para a criação do painel de desempenho. O painel de Desempenho da EdUFSC foi desenvolvido com a intensão de definir os indicadores de desempenho que traduzam a informação de alcance dos objetivos, fixando a descrição de metas, assim como o Score de cada meta, oferecendo ações ou iniciativas que aprimorem a gestão da Editora da UFSC, conforme o Quadro 3. Com a aplicação do modelo a avaliação global da Editora da UFSC, que o seu cenário atual tem uma pontuação de 8 pontos negativos e apresenta drástica alteração para uma pontuação de 86 pontos positivos, aprimorando diversas perspectivas, e tendo o alinhamento ao objetivo institucional, com a aplicação do método.

Com a apresentação de todas as etapas de estruturação do modelo de Balanced Scorecard aplicados à Editora da Universidade Federal de Santa Catarina é pertinente afiançar que os objetivos deste estudo sustentam a coerência no desenvolvimento do alinhamento estratégico da Editora da UFSC com o plano institucional da Universidade Federal de Santa Catarina.

Respondendo a questão problema da pesquisa: "Quais indicadores estão alinhados a estratégia, de autossustentação, para gerenciamento da Editora da Universidade Federal de Santa Catarina?", o estudo trouxe o fundamento científico para a identificação e alinhamento da Editora à estratégia institucional da UFSC, expôs mapa estratégico e painel de desempenho por BSC que definiu quais os indicadores que estão alinhados à estratégia, assim como propôs ações e iniciativas que possam aprimorar a gestão e a sua influência na análise gráfica e melhoraram a avaliação global, pelo método escolhido.

Como limitador do estudo aborda-se a pouca literatura direcionada para editoras universitárias, a fim de ter comparabilidade das informações e a possibilidade de não aplicação do estudo por parte da gestão pode limitar o estudo a ser apenas teórico, e não possibilitando as contribuições do método na prática organizacional.

É importante salientar que o processo do estudo foi contribuinte, também, para a criação de metas, verificação de objetivos e auxílio no desenvolvimento no PDI UFSC (20202024), no que tange à Editora da UFSC. A abrangência de pesquisas sobre avaliação de 
desempenho integra possibilidades distintas, porém, como lacuna de pesquisa pode-se fazer o estudo em outra editora universitária, com as mesmas características e fazer a comparabilidade das informações colhidas, indicando se apresenta melhora na gestão com a aplicação do método BSC, assim como avaliar todos os pontos semelhantes sobre os objetos de estudos. Ou instituir modelos distintos para avaliação de desempenho de instituições públicas de ensino e observar orientações que melhorem a gestão das instituições. Como também, verificar a percepção dos gestores dessas instituições sobre o que pode contribuir com a gestão se for implementado o modelo BSC, ou verificar se alguma instituição já aplicou o BSC e quais os reflexos práticos.

\section{REFERÊNCIAS}

AL-TURKI, U.; DUFFUAA, S. Performance measures for academic departments. International Journal of Educational Management, v. 17, n. 7, p. 330-338, 2003.

BEUREN, I. M. Como elaborar trabalhos monográficos em contabilidade. 3. ed. São Paulo: Atlas, 2006.

BITITCI, U. S.; CARRIE, A. S. MCDEVITT, L. Integrated performance measurement systems: a development guide. International journal of operations \& production management, v. 17, n. 5, p. 522-534, 1997. DOI: https://10.1108/01443579710167230.

BOLAND, T.; FOWLER, A. A systems perspective of performance management in public sector organizations. International Journal of Public Sector Management, v. 13, n. 5, p. 417-446, 2000. DOI: https://doi.org/10.1108/09513550010350832.

BRYSON, J. M.; CROSBY, B. C.; BLOOMBERG, L. Public value governance: moving beyond traditional public administration and the new public management. Public administration review, v. 74, n. 4, p. 445-456, 2014. DOI: https://doi.org/10.1111/puar.12238.

CERVO, A. L.; BERVIAN, P. A. Metodologia científica. 5. ed. São Paulo: Prentice Hall, 2002.

CHEN, S. H.; WANG, H. H.; YANG, K. J. Establishment and application of performance measure indicators for universities. The TQM Journal, v. 21, n. 3, p. 220-235, 2009. DOI: https://doi.org/10.1108/17542730910953004.

CHEN, S. H.; YANG, C. C.; SHIAU, J. Y. The application of Balanced Scorecard in the performance evaluation of higher education. The TQM magazine, v. 18, n. 2, p. 190-205, 2006. DOI: http://dx.doi.org/10.1108/09544780610647892.

CHIAVENATO, I.; SAPIRO, A. Planejamento estratégico: fundamentos e aplicações. 1. ed. Rio de Janeiro: Elsevier, 2003.

COELHO, G. N. et al. Construção de um painel estratégico baseado nas perspectivas do Balanced Scorecard para o departamento de finanças da UFSC. Revista de Administração de Roraima, v. 7, n. 2, p. 382-401, 2017. DOI: http://dx.doi.org/10.18227/2237-

8057rarr.v7i2.4488. 
Elaboração do Balanced Scorecard alinhado aos objetivos da Universidade Federal de Santa Catarina: Um estudo de caso na Editora da UFSC

COELHO, G. N. Balanced Scorecard: uma análise bibliométrica com base na Web of Science de 1992-2017. Revista UNEMAT de Contabilidade, v. 8, n. 15, 2019. Disponível em: https://ocs.ufgd.edu.br/index.php?conference=scf\&schedConf=siconf2018\&page=paper\&op =viewFile \&path\%5B\%5D=529\&path\%5B\%5D=523. Acesso em: 20 ago. 2019.

COSTA, J. H.; SOUZA, R. J. de; PETRI, S. M. Balanced Scorecard: um estudo de caso na Universidade Federal de Santa Catarina. Revista Brasileira de Administração Científica, v. 10, n. 1, p. 77-88, 2019. DOI: https://doi.org/10.6008/CBPC2179-684X.2019.001.0007.

DAYCHOUW, M. 40 Ferramentas e técnicas de gerenciamento. Rio de Janeiro: Brasport, 2007.

DE ANDRADE, E. L. Introdução à pesquisa operacional: métodos e modelos para a análise de decisão. Livros Técnicos e Científicos, 1998.

DIMITROPOULOS, P.; KOSMAS, I.; DOUVIS, I. Implementing the balanced scorecard in a local government sport organization. International Journal of Productivity and Performance Management, v. 66, n. 3, p. 362-379, 2017. DOI: http://10.1108/IJPPM-11-2015-0167.

ENSSLIN, L. et al. Avaliação do desempenho de empresas terceirizadas com o uso da metodologia multicritério de apoio à decisão-construtivista. Pesquisa Operacional, v. 30, n. 1, p. 125-152, 2010. DOI: https://doi.org/10.1590/S0101-74382010000100007.

GIL, A. C. Como elaborar projetos de pesquisa. 4. ed. São Paulo: Atlas, 2008.

GODOY, A. S. Introdução à pesquisa qualitativa e suas possibilidades. Revista de Administração de Empresas, São Paulo, v. 35, p. 20-29, mar./abr. 1995. Disponível em: https://www.scielo.br/pdf/rae/v35n2/a08v35n2.pdf. Acesso em: 15 abr. 2021.

HERBOHN, K. et al. Using a balanced scorecard to improve the management of natural resources: experiences from Baden-Württemberg. Society \& Natural Resources, v. 26, n. 8, p. 865-882, 2013. DOI: https://10.1080/08941920.2012.719999.

INSTITUTO NACIONAL DE ESTUDOS E PESQUISAS EDUCACIONAIS ANÍSIO TEIXEIRA (INEP). Sinopse estatística da educação superior, 2017. Disponível em: http://portal.inep.gov.br/artigo/-/asset_publisher/B4AQV9zFY7Bv/content/divulgados-osmicrodados-e-a-sinopse-estatistica-do-censo-da-educacao-superior-2016/21206. Acesso em: 15 abr. 2021.

ISMAIL, T. H.; AL-THAOIEHIE, M. A Balanced Scorecard model for performance excellence in Saudi Arabia's higher education sector. International Journal of Accounting, Auditing and Performance Evaluation, v, 11, n. 3-4, p. 255-280, 2015. DOI: https://10.1504/IJAAPE.2015.071574.

KANJI, G.; MOURA SÁ, P. Performance measurement and business excellence: the reinforcing link for the public sector. Total Quality Management \& Business Excellence, v. 
18, n. 1-2, p. 49-56, 2007. DOI: https://10.1080/14783360601043096.

KAPLAN, R. S.; NORTON, D. P. The Balanced Scorecard: measures that drive performance. Harvard business review, v. 70, p. 71-79, 1992. Disponível em: http://planuba.orientaronline.com.ar/wp-content/uploads/2010/03/harvard-businessreview-kaplan-norton-the-balanced-scorecard-measures-that-drive-performance.pdf. Acesso em: 21 abr. 2021.

KAPLAN, R. S.; NORTON, D.P. Putting the Balanced Scorecard to work. Harvard Business Review, Boston, v. 71, n. 5, p. 134-147, out./nov. 1993. Disponível em:

https://hbr.org/1993/09/putting-the-balanced-scorecard-to-work. Acesso em: 21 abr. 2021.

KAPLAN, R. S.; NORTON, D. P. A estratégia em ação: Balanced Scorecard. Rio de Janeiro: Campus, 1997.

KAPLAN, R. S.; NORTON, D. P. Organização orientada para a estratégia: como as empresas que adotam o Balanced Scorecard prosperam no novo ambiente de negócios. Rio de Janeiro: Campus, 2000.

KETTUNEN, J. A conceptual framework to help evaluate the quality of institutional performance. Quality Assurance in Education, p. 16, n. 4, p. 322-332, 2008. DOI: https://10.1108/09684880810906472.

KOTLER, P. Administração de Marketing. 10. ed. São Paulo: Pearson Prentice Hall, 2000.

LAKATOS, E.; MARCONI, M. Fundamentos de metodologia científica. São Paulo: Atlas, 2010.

LEBAS, M. J. Performance measurement and performance management. International Journal of Production Economics, v. 41, n. 1-3, p. 23-35, 1995. DOI: https://10.1016/09255273(95)00081-X.

LONGARAY, A. A. Introdução à pesquisa operacional. Saraiva Educação SA, 2017.

LUNKES, R. J. Contabilidade gerencial: um enfoque na tomada de decisão. Florianópolis: Visual Books, 2007.

MARCONI, M.; LAKATOS, E. M. Técnicas de pesquisa. 3. ed. São Paulo: Atlas, 1999.

NEELY, A. The evolution of performance measurement research: developments in the last decade and a research agenda for the next. International Journal of Operations \& Production Management, v. 25, n. 12, p. 1264-1277, 2005. DOI: https://10.1108/01443570510633648.

NEELY, A.; GREGORY, M.; PLATTS, K. Performance measurement system design: a literature review and research agenda. International Journal of Operations \& Production Management, v. 15, n. 4, p. 80-116, 1995. Disponível em: https://www.leanway.com.br/wpcontent/uploads/Neely.pdf. Acesso em: 21 abr. 2021. 
Elaboração do Balanced Scorecard alinhado aos objetivos da Universidade Federal de Santa Catarina: Um estudo de caso na Editora da UFSC

NUDURUPATI, S. S. et al. State of the art literature review on performance measurement. Computers \& Industrial Engineering, v. 60, n. 2, p. 279-290, 2011. DOI: https://doi.org/10.1016/j.cie.2010.11.010.

NUTI, S.; SEGHIERI, C.; VAINIERI, M. Assessing the effectiveness of a performance evaluation system in the public healthcare sector: some novel evidence from the Tuscany region experience. Journal of Management \&Governance, v. 17, n. 1, p. 59-69, 2013. DOI: https://doi.org/10.1007/s10997-012-9218-5.

OTLEY, D. Extending the boundaries of management accounting research: developing systems for performance management. The British Accounting Review, v. 33, n. 3, p. 243 261, 2001.

PAPENHAUSEN, C.; EINSTEIN, W. Implementing the Balanced Scorecard at a college of business. Measuring Business Excellence, v. 10, n. 3, p. 15-22, 2006.

PEREIRA, D.; TERRA, L. A. A. Barreiras Impostas pela Cultura na Implantação de Balanced Scorecard em uma Indústria de Alimentos. Revista Eletrônica de Estratégia \& Negócios, v. 9, n. 1, p. 3-25, 2016. DOI: http://dx.doi.org/10.19177/reen.v9e120163-25.

PETRI, S. M. Modelo para apoiar a avaliação das abordagens de gestão de desempenho e sugerir aperfeiçoamento: sob a ótica construtivista. 2005. 236 f. Tese (Doutorado em Engenharia da Produção) - Universidade Federal de Santa Catarina, Florianópolis, 2005.

PHILBIN, S. P. Design and implementation of the Balanced Scorecard at a university institute. Measuring Business Excellence, v. 15, n. 3, p. 34-45, 2011. DOI: https://doi.org/10.1108/13683041111161148.

PIETRZAK, M.; PALISZKIEWICZ, J.; KLEPACKI, B. The application of the Balanced Scorecard (BSC) in the higher education setting of a Polish university. Journal of Applied Knowledge Management, v. 3, n. 1, p. 151-164, 2015. Disponível em:

https://www.researchgate.net/publication/280309682_The_application_of_the_balanced_s corecard_BSC_in_the_higher_education_setting_of_a_Polish_university. Acesso em: 21 abr. 2021.

RADNOR, Z.; MCGUIRE, M. Performance management in the public sector: fact or fiction? International Journal of Productivity and Performance Management, v. 53, n. 3, p. 245-260, 2004. DOI: https://doi.org/10.1108/17410400410523783.

RODRIGUES, J. N. et al. 50 gurus para o século XXI. 1. ed. Lisboa: Centro Atlântico, 2005.

ROSA, M. M. et al. O Balanced Scorecard como ferramenta de gestão estratégica e orçamentária da Fundação Cultural de Florianópolis. Revista Evidenciação Contábil \& Finanças, João Pessoa v. 2, n. 1, p. 39-58, 2014. DOI: http://10.18405/recfin20140103.

SCHALM, C. Implementing a Balanced Scorecard as a strategic management tool in a long- 
term care organization. Journal of Health Services Research \& Policy, v. 13, supl. 1, p. 8-14, 2008. DOI: https://doi.org/10.1258/jhsrp.2007.007013.

SENARATH, S. A. C. L.; PATABENDIGE, S. S. J. Balance Scorecard: translating corporate plan into action: a case study on University of Kelaniya, Sri Lanka. Procedia-Social and Behavioral Sciences, v. 172, p. 278-285, 2015. DOI: https://doi.org/10.1016/j.sbspro.2015.01.365.

SILVEIRA, M.; ENSSLIN, S. R. Avaliação de desempenho em instituições de ensino superior: revisão de literatura e oportunidades para futuras pesquisas. In: Colóquio Internacional de Gestão Universitária (CIGU), 17., Mar Del Plata, Argentina, nov. 2017. Anais [...]. Mar Del Plata, Argentina, 2017.

SILVEIRA, M.; PETRI, S. M. Elaboração do Balanced Scorecard para alinhamento estratégico: estudo de caso no DAP-IFC. Revista Gestão \& Planejamento, v. 20, n. 1, p. 126-148, jan./dez. 2019. DOI: https://10.21714/2178-8030gep.v.20.5751.

SOUZA, P. et al. Development of Balanced Scorecard as a strategic management for a graduate program. IEEE Latin America Transactions, v. 13, n. 1, p. 277-283, 2015.

TAPINOS, E.; DYSON, R. G.; MEADOWS, M. The impact of the performance measurement systems in setting the 'direction' in the University of Warwick. Production Planning \& Control, v. 16, n. 2, p. 189-198, 2005. DOI: https://10.1080/09537280512331333084.

TAYLOR, J.; BAINES, C. Performance management in UK universities: implementing the Balanced Scorecard. Journal of Higher Education Policy and Management, v. 4, n. 2, p. 111 124, 2012. DOI: https://doi.org/10.1080/1360080X.2012.662737.

UNIVERSIDADE FEDERAL DE SANTA CATARINA (UFSC). Editora Universitária. 2019. Disponível em: http://editora.ufsc.br/. Acesso em: 13 maio 2019.

UNIVERSIDADE FEDERAL DE SANTA CATARINA (UFSC). Plano de Desenvolvimento Institucional - PDI, 2015-2019. 2015. Disponível em:

http://pdi.ufsc.br/files/2018/10/Relat\%C3\%B3rio-Acompanhamento-PDI-20152018.pdf1.pdf. Acesso em: 10 out. 2019.

VAN CAMP, J.; BRAET, J. Taxonomizing performance measurement systems' failures. International Journal of Productivity and Performance Management, v. 65, n. 5, p. 672-693, 2016. Disponível em: https://ideas.repec.org/a/eme/ijppmp/v65y2016i5p672-693.html. Acesso em: 21 abr. 2021.

VERBEETEN, F. H. Performance management practices in public sector organizations: impact on performance. Accounting, Auditing\& Accountability Journal, v. 21, n. 3, p. 427-454, 2008. https://doi.org/10.1108/09513570810863996. 